\title{
A Detailed Neuroscientific Framework for the Multiple Intelligences: Describing the Neural Components for Specific Skill Units within Each Intelligence
}

\author{
C. Branton Shearer ${ }^{1}$ \\ ${ }^{1}$ MI Research and Consulting, Inc., USA \\ Correspondence: C. Branton Shearer, MI Research and Consulting, Inc., USA. E-mail: sbranton@kent.edu
}

Received: May 14, 2019

Accepted: June 18, 2019

Online Published: June 19, 2019

doi:10.5539/ijps.v11n3p1

URL: https://doi.org/10.5539/ijps.v11n3p1

Supplemental Information cited in this article may be requested from the author.

\begin{abstract}
The concept of intelligence has been debated since introduction of IQ tests in the early 1900s. Numerous alternatives to unitary intelligence have achieved limited acceptance and IQ remains the predominant theoretical basis for schooling. Multiple intelligences theory (Gardner, 1983), despite criticism it lacks experimental validity, has had sustained interest by educators worldwide as a means of personalizing instruction and curriculum. The neuroscientific evidence for the intelligences has not been updated since 1983. This investigation reviewed 417 neuroscientific studies examining neural correlates for skill units within seven intelligences. Neural activation patterns demonstrate each skill unit has its own unique neural underpinnings as well as neural features shared with other skill units within its designated intelligence. These patterns of commonality and uniqueness provide richly detailed neural architectures in support of MI theory as a scientific model of human intelligence. This conclusion is supported by four previous studies revealing extensive neural evidence that MI theory distinguishes among ability groups and several cognitive qualities (Shearer and Karanian, 2017). The emerging field of educational cognitive neuroscience strives to bridge the gap between laboratory findings and classroom instruction. MI theory aligns with advances in understanding how the mind and brain interact providing a practical interface between the art of teaching and neuroscience. A neuroscientific model of the multiple intelligences brings us closer to the goal of personalizing education by understanding the unique neuro-cognitive profiles of all students. These findings, coupled with advanced technologies, point the way forward to bring MI-inspired education to all students.
\end{abstract}

Keywords: intelligence, multiple intelligences, cognitive components, skills, neuro-cognitive substrates

\section{Introduction}

The concept of intelligence has had a contentious history as both an educational and scientific theory. Despite decades of criticism, it remains either explicitly or implicitly the basis for educational systems around the world. Many researchers have abandoned the concept - in part or entirely - and instead investigate cognitive abilities, problem-solving, or information processing capacities. However, many scientists have also investigated the functional neural systems that underlie intellectual achievement. The reason for this has been summed up succinctly by Jung and Haier (2007, p. 171) “...there is no more important concept in education than the concept of intelligence." They assert that not all brains are wired the same way, thus "this simple fact could be revolutionary for education because it demands a neuroscience approach that recognizes the importance of individual differences and the necessity to evaluate each student as an individual." (2008, p. 174).

The goal of designing education that can personalize instruction and curriculum according to each student's unique neural and intellectual configuration is as noble as it is elusive. The shear complexity of the brain's neural architecture presents a formidable challenge to connecting its functions to pedagogy. In 1997 Bruer (1997) voiced doubts that neuroscience alone could bridge between the lab and the classroom - however, much progress has been made since then. Certainly, there has been movement beyond the "pop psychology" of brain-based teaching notions toward a more fully realized field of educational cognitive neuroscience. This progress has been mirrored in our conceptualization of what constitutes human intelligence. 
The theory of multiple intelligences (MI) is of primary interest to the present investigation. In his seminal book, Frames of Mind, Howard Gardner $(1983,1999)$ redefined intelligence as the ability to solve problems or create products of value in a culture or community. Using this broad, common-sense definition and criteria* that cover a range of evidence (e.g., neuroscience, psychometric and evolutionary evidence, and atypical populations), Gardner identified eight distinct forms of intelligence that are possessed by all people, but in varying degrees. The eight intelligences identified are linguistic, logical-mathematical, spatial, kinesthetic, musical, interpersonal, intrapersonal and naturalist (see Table 1 and for detailed descriptions Supplemental Information A1).

Table 1. Details of Neuroscience Literature Review for Multiple Intelligences

\begin{tabular}{|c|c|c|c|c|c|c|c|}
\hline Intelligence & $\begin{array}{l}\text { Search } \\
\text { terms }\end{array}$ & Ref. & Years & $\begin{array}{l}\text { Criteria Groups } \\
\text { in Studies }\end{array}$ & $\begin{array}{l}\text { Neural } \\
\text { Regions cited } \\
\text { originally }\end{array}$ & $\begin{array}{l}\text { Core } \\
\text { Cognitive Skill } \\
\text { Units }\end{array}$ & 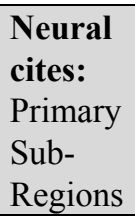 \\
\hline Linguistic & $\begin{array}{l}\text { Verbal skill } \\
\text { Reading } \\
\text { Writing } \\
\text { Speaking } \\
\text { Rhetoric }\end{array}$ & $\begin{array}{l}37 \\
\text { incl. } \\
7 \\
\text { rsFC }\end{array}$ & $\begin{array}{l}1998- \\
2015\end{array}$ & $\begin{array}{l}\text { Creative Writing } \\
\text { Chinese skilled } \\
\text { Skilled Reading } \\
\text { Typical }\end{array}$ & $\begin{array}{l}\text { Broca's area in } \\
\text { left inferior } \\
\text { frontal cortex, } \\
\text { Wernicke's } \\
\text { area in the left } \\
\text { temporal lobe, } \\
\text { lateral sulcus } \\
\text { loop inferior } \\
\text { parietal lobule }\end{array}$ & $\begin{array}{l}\text {-Speech } \\
\text {-Reading } \\
\text {-Writing } \\
\text {-Multimodal } \\
\text { Communication } \\
\text { of Meaning }\end{array}$ & $\begin{array}{l}\text { Primary: } \\
156 \\
\text { SubReg: } \\
93\end{array}$ \\
\hline $\begin{array}{l}\text { Logical-math } \\
\text { ematical }\end{array}$ & $\begin{array}{l}\text { Reasoning } \\
\text { Calculations } \\
\text { Math skill } \\
\text { Abstraction } \\
\text { Meaning- } \\
\text { making }\end{array}$ & $\begin{array}{l}32 \\
\text { Incl. } \\
1 \\
\text { rsFC }\end{array}$ & $\begin{array}{l}2000- \\
2013\end{array}$ & $\begin{array}{l}\text { Chess Masters } \\
\text { Calculus } \\
\text { Math Prodigy } \\
\text { High IQ } \\
\text { Language }\end{array}$ & $\begin{array}{l}\text { Left parietal } \\
\text { lobes \& } \\
\text { adjacent } \\
\text { temporal \& } \\
\text { occipital } \\
\text { association } \\
\text { areas, left } \\
\text { hemisphere for } \\
\text { verbal naming, } \\
\text { right } \\
\text { hemisphere for } \\
\text { spatial } \\
\text { organization, } \\
\text { frontal system } \\
\text { for planning } \\
\text { and goal setting }\end{array}$ & $\begin{array}{l}\text {-Mathematical } \\
\text { Reasoning } \\
\text {-Logical } \\
\text { Reasoning } \\
\text { - General } \\
\text { Intelligence }(g)\end{array}$ & $\begin{array}{l}\text { Primary: } \\
99\end{array}$ \\
\hline Musical & $\begin{array}{l}\text { Vocal/ } \\
\text { Singing } \\
\text { Instrumental } \\
\text { ability } \\
\text { Musical } \\
\text { appreciation } \\
\text { Improvisation } \\
\text { Music } \\
\text { emotions }\end{array}$ & $\begin{array}{l}77 \\
\text { Incl. } \\
4 \\
\text { rsFC }\end{array}$ & $\begin{array}{l}1985- \\
2013\end{array}$ & $\begin{array}{l}\text { Pianists } \\
\text { Singers } \\
\text { Musicians } \\
\text { Violinists }\end{array}$ & $\begin{array}{l}\text { Right anterior } \\
\text { temporal and } \\
\text { frontal lobes }\end{array}$ & $\begin{array}{l}\text {-Musical } \\
\text { Perception } \\
\text {-Musical } \\
\text { Production } \\
\text { - Musical } \\
\text { Cognition } \\
\text { - } \\
\text { Melody-Pitch- } \\
\text { Rhythm }\end{array}$ & $\begin{array}{l}\text { Primary: } \\
338\end{array}$ \\
\hline Kinesthetic & $\begin{array}{l}\text { Large motor } \\
\text { movement } \\
\text { Fine motor } \\
\text { Dexterity } \\
\text { Tool use }\end{array}$ & $\begin{array}{l}60 \\
\text { Incl. } \\
3 \\
\text { rsFC }\end{array}$ & $\begin{array}{l}1977- \\
2015\end{array}$ & $\begin{array}{l}\text { Dancers } \\
\text { Pianists } \\
\text { Violinists } \\
\text { Athletes }\end{array}$ & $\begin{array}{l}\text { Cerebral motor } \\
\text { strip, thalamus, } \\
\text { basal ganglia, } \\
\text { cerebellum }\end{array}$ & $\begin{array}{l}\text {-Body } \\
\text { Awareness } \\
\text {-Whole Body } \\
\text { Movement } \\
\text {-Dexterity }\end{array}$ & $\begin{array}{l}\text { Primary: } \\
233\end{array}$ \\
\hline
\end{tabular}




\begin{tabular}{|c|c|c|c|c|c|c|c|}
\hline \multirow[b]{2}{*}{ Spatial } & $\begin{array}{l}\text { Eye-Hand } \\
\text { coordination } \\
\text { Dance } \\
\text { Athletics }\end{array}$ & & & $\begin{array}{l}\text { Golfers } \\
\text { Instrumentalists }\end{array}$ & & $\begin{array}{l}\text {-Motor } \\
\text { Cognition } \\
\text {-Symbolic } \\
\text { Movement }\end{array}$ & 318 \\
\hline & $\begin{array}{l}\text { Mental } \\
\text { visualization } \\
\text { Imagination } \\
\text { Spatial } \\
\text { orientation }\end{array}$ & $\begin{array}{l}49 \\
\text { Incl. } \\
3 \\
\text { rsFC }\end{array}$ & $\begin{array}{l}1978- \\
2015\end{array}$ & $\begin{array}{l}\text { Strategy Games } \\
\text { Creativity } \\
\text { Chess } \\
\text { Memory } \\
\text { Golf } \\
\text { Badminton } \\
\text { Gestures } \\
\text { Symbolic }\end{array}$ & $\begin{array}{l}\text { Right parietal } \\
\text { posterior, } \\
\text { occipital lobe }\end{array}$ & $\begin{array}{l}\text {-Spatial } \\
\text { Cognition } \\
\text {-Working with } \\
\text { Objects } \\
\text {-Visual Arts } \\
\text { - } \\
\text { Insight-Intuitio } \\
\text { n }\end{array}$ & $\begin{array}{l}\text { SubReg: } \\
308\end{array}$ \\
\hline Interpersonal & $\begin{array}{l}\text { Empathy } \\
\text { Theory } \\
\text { of mind } \\
\text { Interpersonal } \\
\text { perspective- } \\
\text { taking } \\
\text { Leadership }\end{array}$ & $\begin{array}{l}61 \\
\text { Inclu } \\
2 \\
\text { rsFC }\end{array}$ & $\begin{array}{l}1989- \\
2013\end{array}$ & $\begin{array}{l}\text { Leaders } \\
\text { Typical }\end{array}$ & $\begin{array}{l}\text { Frontal lobes as } \\
\text { integrating } \\
\text { station, limbic } \\
\text { system }\end{array}$ & $\begin{array}{l}\text {-Social } \\
\text { Perception } \\
\text {-Interpersonal } \\
\text { Understanding } \\
\text {-Social } \\
\text { Effectiveness } \\
\text {-Leadership }\end{array}$ & $\begin{array}{l}\text { Primary: } \\
93\end{array}$ \\
\hline Intrapersonal & $\begin{array}{l}\text { Metacognition } \\
\text { Emotional } \\
\text { intelligence } \\
\text { Self-manage } \\
\text { ment } \\
\text { Impulse } \\
\text { control }\end{array}$ & $\begin{array}{l}101 \\
\text { Incl. } \\
4 \\
\text { rsFC }\end{array}$ & $\begin{array}{l}1998- \\
2014\end{array}$ & $\begin{array}{l}\text { Meditation } \\
\text { Auto Memory } \\
\text { Mindfulness } \\
\text { Prospective } \\
\text { Memory } \\
\text { Happiness } \\
\text { Typical }\end{array}$ & $\begin{array}{l}\text { Frontal lobe } \\
\text { system }\end{array}$ & $\begin{array}{l}\text {-Self-Awarenes } \\
\mathrm{s} \\
\text {-Self-Regulatio } \\
\mathrm{n} \\
\text {-Executive } \\
\text { Functions } \\
\text {-Self-Other } \\
\text { Management }\end{array}$ & $\begin{array}{l}\text { Primary: } \\
253\end{array}$ \\
\hline Naturalist & $\begin{array}{l}\text { Understanding } \\
\text { animals } \\
\text { Plant care } \\
\text { Science } \\
\text { Classification }\end{array}$ & 0 & & & $\begin{array}{l}\text { Left parietal } \\
\text { lobe for } \\
\text { discriminating } \\
\text { living from } \\
\text { non-living } \\
\text { entities }\end{array}$ & $\begin{array}{l}\text {-Pattern } \\
\text { Cognition } \\
\text {-Understanding } \\
\text { Living Entities } \\
\text {-Understanding } \\
\text { Animals } \\
\text {-Understanding } \\
\text { Plant Life } \\
\text {-Science }\end{array}$ & \\
\hline & Totals & $\begin{array}{l}417 \\
24(\mathrm{rs}\end{array}$ & & & & $\begin{array}{l}\text { Primary Total } \\
1372\end{array}$ & $=$ \\
\hline & & & & & & Sub-Region Tot & $=1969$ \\
\hline
\end{tabular}

Sources. (Gardner, 1983, 1999); Shearer, \& Karanian, 2017).

\subsection{Theoretical Models of Intelligence}

Traditional psychologists have criticized MI theory since its inception (Waterhouse, 2006b). A criticism of MI theory is that it lacks support from large scale studies (Herrnstein \& Murray, 1994; Waterhouse, 2006a) or experimental research (Sternberg, 1996; Traub \& Gardner, 1999: Waterhouse, 2006a). It has also been proposed that the eight intelligences are simply different manifestations of general intelligence (Jensen, 1999; Visser, Ashton \& Vernon, 2006). An important practical criticism is that educators should not base instructional and 
curricular decisions upon a theory that lacks support from neuroscience evidence (Gerin \& Fien, 2016; Hale, 2016). and is controversial (Gottfredson, 2004; White, 1988; Willingham, 2004).

Among neuroscientists, the predominant view on intelligence is that there is either one general intelligence $(g)$ or two types of intelligence (fluid and crystallized). However, there is a debate regarding the possible sub-divisions of intelligence and how each sub-division relates to " $g$ " (Barbey, et al., 2012; Basten, Hilger \& Fiebach, 2015; Duncan, et al, 2000; Jung \& Haier, 2007). Numerous other theories that deviate from the unitary intelligence theory - including triarchic (Sternberg, 1988), emotional intelligence (Goleman, 1995; Salovey \& Mayer, 1990), structure of intellect (Guilford, 1954), faculties of mind (Thurstone, 1938), and cognitive styles (Kolb \& Kolb, 2005) - have had noteworthy, but limited, influence. Many have been recognized by the field of psychology, but not embraced by educators. Few have had the lasting and profound impact on education as multiple intelligences theory, which is still of interest worldwide more than 30 years after its introduction (Chen, Moran \& Gardner, 2009). Despite this broad appeal to educators, MI remains more of an inspirational educational framework rather than a fully developed scientific theory (Brody, 1992; Chomsky, 2009).

\subsection{Research Investigating MI Theory}

Some researchers classify MI theory as a "neuro-myth" due to a paucity of research into its essential neuroscientific validity (Tokuhama-Espinosa, 2010). Gardner was one of the first modern theorists to associate intelligence with specific brain regions in the early 1980s (see Table 1; column 6). Since the arrival of functional neuroimaging in the 1990s, neuroscientists have extensively studied the neural underpinnings of human cognition - including the concept of general intelligence.

A recent review of 318 neuroscience studies compared the neural evidence for general intelligence to each of the identified multiple intelligences and concluded "...there is a degree of coherence and uniqueness among the particular neural structures identified for each intelligence that are comparable to what has been observed for general intelligence" (Shearer \& Karanian, 2017).

This investigation provided a three-dimensional framework where the neural bases for each intelligence were described in terms of primary regions, sub-regions, and particular structures. These neural frameworks have cognitive correlates that are generally well-aligned with skillsets associated with each intelligence. The localization of cognitive-behavioral functions in the brain provides an important yet incomplete understanding of brain functionality. The interaction among brain regions provides more information about how various neural regions are activated in a coordinated manner. The study of correlated brain structures that form neural networks occurs during both task-based experiments and, also, while the brain is "at rest."

A second, in-depth analysis of 48 experiments examining resting-state neural connectivity (rsFC) found clear correspondences among several rsFC networks and seven of the multiple intelligences (naturalist not included) (Shearer, 2017a). This investigation tested the alignment between rsFC neural networks and MI from two perspectives. First, thirteen whole-brain, model-free rsFC studies found 15 networks were aligned to the seven intelligences. Second, thirty-five region-of-interest rsFC studies revealed 21 networks to be matched to the same intelligences (and their core cognitive components). These findings reinforce the previous evidence from task-based research that there are coherent neural networks underpinning each of the multiple intelligences. For example, for kinesthetic intelligence four model-free networks were identified: Primary Motor, SensoriMotor, Cerebellar and Basal Ganglia. It was also evident that there are meaningful individual differences in how each person's brain responds to and processes stimuli (Sadaghiani, et al, 2010).

A third review of 420 neuroscience reports examined the neural differences for each of the multiple intelligences among people with varying levels of ability. This study concluded that there are distinct neural differences among skilled, typical, and impaired people for seven of the eight intelligences (Shearer, 2017b). Of particular note, are the large number of negative activations cited for neural regions for the impaired groups that are the same neural regions that are among the highest cited for the other two groups. It is also of interest that there are intriguing neural differences between the typical and skilled groups in surprising ways. For example, for linguistic the typical group is dominated by the temporal $(41 \%)$ followed by frontal $(29 \%)$. In contrast, the linguistic regions for the skilled group are dominated by frontal (27\%) followed by occipital (17\%) and then in third place is temporal at $(16 \%)$.

These three investigations provide robust evidence that there are distinct neural frameworks for the multiple intelligences that are associated with both task-based activities and resting-state networks. These neural differences are also evident among ability groups in patterns aligned with both MI theory and cognitive behaviors associated with general intelligence. This evidence is, however, incomplete. A fully realized theory of 
intelligence needs to provide a sufficient level of detail to facilitate both scientific measurement and bridging between educational cognitive neuroscience and classroom practices.

\subsection{Hypotheses}

The following review of 417 neuroscience reports organizes 30 years of neural data according to the core skill units within each of seven intelligences. Naturalist is not included due to a limited number of studies available for its skill units. The goal is to determine if neuroscience evidence describes the neural differences and commonalities among three or four skill units within each intelligence as predicted by MI theory.

\section{Procedures}

\subsection{Data Collection Steps}

This is the fifth study of the neuroscience literature that began with a detailed review of the various cognitive units and specific skills associated with the multiple intelligences. For example, musical intelligence includes instrumental, vocal, composing and appreciation. Each of these ability sets includes technical skill as well as creative performance (e.g., singing on key and jazz improvisation) so the review of musical neuroscience studies would ideally be inclusive of this range of abilities. Charts were constructed for each intelligence with rows for MI cognitive units and columns for matched neural structures and cognitive skills (linguistic sample in Supplemental Information (SI) A2). All data is available upon request).

Using the terms related to each cognitive unit or specific skill (Table 1, column 2), PubMed or Google Scholar were used to search for published peer-reviewed empirical neuroscience studies (see journals list in SI-A4). Studies of personality characteristics or dispositions were not included (e.g., introversion, diligence, etc.). Theoretical articles or books were used for background information. Several extensive meta-analysis and topic reviews served as guides to finding pertinent studies in the target area (Blair, 2006; Duncan, 2013; Posner, 2013; Posner, Rothbart, Sheese \& Kieras, 2008). Over 417 articles were referenced for the seven intelligences. Three hundred and eighteen of these reports were used during phase one, which examined the neural correlates for the eight intelligences with an emphasis on task-based functional neuroimaging experiments (Shearer \& Karanian, 2017). An additional 24 of rsFC studies were added to the original data along with studies that focused on the neural characteristics of a specific ability group (skilled, impaired, or typical).

The minimum number of studies for the current investigation was 32 for logical-mathematical with a maximum of 101 for intrapersonal (mean=60) (Table 1, column 3).

From this dataset excerpts from each text describing neural activations associated with carefully defined cognitive skills were entered into the charts per Cognitive Unit (see linguistic -sample in Supplemental Information A2). All neural regions were then put into an Excel spreadsheet and reorganized based on neural hierarchy (Supplemental Information A3 and A5).

Neuroscience researchers use a variety of neuroanatomical labels and the specificity of regions evolved as the neuroimaging technology advanced. Some researchers identify broad regions with a single label while others use multiple terms to identify sub-regions. Still others use Brodmann numbering, Talairach Atlas, or the MNI Coordinate system. This variety of nomenclatures required a careful translation and mapping onto the three-level hierarchy (primary, sub-regions, multi-regions) described below.

Our analysis of this data employed both qualitative and quantitative methods to determine if a three-dimensional view of the neural structures associated with skill units within each intelligence could be created. This hybrid approach - qualitative and quantitative - reflects both the evolution of the field as well as our understanding of how the brain processes information - from very specific to diffuse patterns of activation.

\subsection{Analyses}

The analysis conducted in the present study is nearly identical to the procedures in our previous investigation (Shearer \& Karanian, 2017). First, we assessed the frequency of cited primary neural regions, which included the frontal cortex, temporal cortex, parietal cortex, occipital cortex, cingulate cortex, insular cortex, subcortical regions, and the cerebellum. We also ran a secondary analysis of several levels of sub-regions within each of the primary regions that were dominant for that intelligence. A third-level summary describes the important particular structures (sub-regions 2 and sub-regions 3) within a sub-region within a primary region (e.g., frontal cortex $\rightarrow$ prefrontal cortex $\rightarrow$ dorsomedial prefrontal cortex (Supplemental Information A3).

Lastly, multi-region neural networks (e.g., cortical-midline-structures, limbic system, corpus callosum, etc.) are examined for the skill units. Neural regions cited are assumed to be positive activations (i.e., the study reported 
an increase in blood oxygen level dependent signal during that particular cognitive process relative to some baseline) unless otherwise specified as "negative."

According to MI theory each intelligence is comprised of specific cognitive skill sets that are unique to that ability but may also be related to each other. Finally, as a benchmark of validity, patterns of neural commonalities and uniquenesses among the eight intelligences were compared to widely accepted neural models for general intelligence $(g)$.

\section{Results}

The following analysis for each intelligence involves a three-level sequence of description. First, the number of citations for eight primary neural regions for the group as a whole are presented. Second, primary region citations for each of three or four skill units are compared. Third, sub-region citations for the whole group are described followed by comparisons among the three or four units. Lastly, multi-region networks for the whole group and each skill unit are described. This is followed by summary descriptions of the highest primary and sub-regions for each group and its skill units.

This analysis involves a wealth of complex data that will be summarized in the following discussion with an emphasis on the primary neural region comparisons. The citation data for all of these summaries (sub-regions and multi-regions) are presented in numerous tables in Supplemental Information.

Table 2. Primary Regions Skill Unit Comparisons: Interpersonal, Intrapersonal, Linguistic \& Logical-mathematical

\section{A Interpersonal: Primary Region Skill Unit Comparisons}

\begin{tabular}{lcclccccc}
\hline Understanding & & \multicolumn{3}{c}{ Leadership } & & \multicolumn{3}{c}{ Social Perception } \\
\hline Regions & ct & $\%$ & Regions & ct & $\%$ & Regions & ct & $\%$ \\
\hline Frontal Cortex & $\mathbf{1 7}$ & $\mathbf{6 8 . 0}$ & Frontal Cortex & $\mathbf{8}$ & $\mathbf{3 0 . 8}$ & Temporal Cortex & $\mathbf{1 4}$ & $\mathbf{4 5 . 2}$ \\
\hline Cingulate Cortex & 5 & 20.0 & Temporal Cortex & $\mathbf{8}$ & $\mathbf{3 0 . 8}$ & Parietal Cortex & 4 & 12.9 \\
\hline Temporal Cortex & 2 & 8.0 & Cingulate Cortex & 4 & 15.4 & Frontal Cortex & 4 & 12.9 \\
\hline Parietal Cortex & 1 & 4.0 & Parietal Cortex & 3 & 11.5 & Subcortical & 4 & 12.9 \\
\hline & & & Occipital Cortex & 1 & 3.8 & Insular Cortex & 2 & 6.5 \\
\hline & & & Subcortical & 1 & 3.8 & Cingulate Cortex & 2 & 6.5 \\
\hline Total & & & Insular Cortex & 1 & 3.8 & Occipital Cortex & 1 & 3.2 \\
\hline $\mathbf{R}$ & 26 & 100 & & 29 & 100 & & 39 & 100 \\
\hline
\end{tabular}

B Intrapersonal: Primary Region Skill Unit Comparisons

\begin{tabular}{lccllllll}
\hline Self-Awareness & \multicolumn{3}{c}{ Self-Regulation } & & \multicolumn{5}{c}{ Executive Functions } \\
\hline Regions & ct & $\%$ & Regions & ct & $\%$ & Regions & ct & $\%$ \\
\hline Frontal Cortex & $\mathbf{6 5}$ & $\mathbf{3 7 . 6}$ & Frontal Cortex & $\mathbf{1 4}$ & $\mathbf{3 0 . 4}$ & Frontal Cortex & $\mathbf{1 1}$ & $\mathbf{5 0 . 0}$ \\
\hline Temporal Cortex & 32 & 18.5 & Temporal Cortex & $\mathbf{1 0}$ & $\mathbf{2 1 . 7}$ & Parietal Cortex & 3 & 13.6 \\
\hline Cingulate Cortex & 29 & 16.8 & Cingulate Cortex & 8 & 17.4 & Subcortical & 3 & 13.6 \\
\hline Parietal Cortex & 20 & 11.6 & Parietal Cortex & 7 & 15.2 & Cingulate Cortex & 3 & 13.6 \\
\hline Subcortical & 15 & 8.7 & Subcortical & 4 & 8.7 & Insular Cortex & 2 & 9.1 \\
\hline Insular Cortex & 10 & 5.8 & Insular Cortex & 3 & 6.5 & & & \\
\hline Cerebellum & 2 & 1.2 & & & & & \\
\hline Total & 173 & 100 & Total & 46 & 100 & Total & 22 & 100
\end{tabular}




\section{Linguistic: Primary Regions Skill Unit Comparisons}

\begin{tabular}{lcclcllll}
\hline \multicolumn{1}{l}{ Speech } & \multicolumn{2}{c}{ Reading } & \multicolumn{2}{l}{ Writing } \\
\hline Regions & ct & $\%$ & Regions & ct & $\%$ & Regions & ct & $\%$ \\
\hline Temporal Cortex & $\mathbf{1 2}$ & $\mathbf{5 2 . 2}$ & Temporal Cortex & $\mathbf{1 3}$ & $\mathbf{3 4 . 2}$ & Frontal Cortex & $\mathbf{1 3}$ & $\mathbf{3 1 . 0}$ \\
\hline Frontal Cortex & 5 & 21.7 & Frontal Cortex & $\mathbf{1 1}$ & $\mathbf{2 8 . 9}$ & Occipital Cortex & $\mathbf{8}$ & $\mathbf{1 9 . 0}$ \\
\hline Parietal Cortex & 4 & 17.4 & Parietal Cortex & $\mathbf{8}$ & $\mathbf{2 1 . 1}$ & Subcortical & 5 & 11.9 \\
\hline Cingulate Cortex & 1 & 4.3 & Occipital Cortex & 2 & 5.3 & Temporal Cortex & 5 & 11.9 \\
\hline Cerebellum & 1 & 4.3 & Cingulate Cortex & 2 & 5.3 & Parietal Cortex & 4 & 9.5 \\
\hline & & & Subcortical & 2 & 5.3 & Cingulate Cortex & 3 & 7.1 \\
\hline & & & & & & Insular Cortex & 2 & 4.8 \\
\hline Total & & & & & & Cerebellum & 2 & 4.8 \\
\hline
\end{tabular}

D $\quad$ Logical-mathematical: Primary Region Skill Unit Comparisons

\begin{tabular}{|c|c|c|c|c|c|c|c|c|}
\hline \multicolumn{3}{|l|}{ Logical Reasoning } & \multicolumn{3}{|c|}{ Mathematical Reasoning } & \multicolumn{3}{|l|}{$G$} \\
\hline Regions & ct & $\%$ & Regions & ct & $\%$ & Regions & ct & $\%$ \\
\hline Temporal Cortex & 15 & 37.5 & Parietal Cortex & 18 & 51.4 & Parietal Cortex & 8 & 33.0 \\
\hline Frontal Cortex & 13 & 32.5 & Frontal Cortex & 11 & 31.4 & Frontal Cortex & 8 & 33.0 \\
\hline Parietal Cortex & 6 & 15.0 & Cingulate Cortex & 4 & 11.4 & Subcortical & 3 & 12.5 \\
\hline Cingulate Cortex & 3 & 7.5 & Cerebellum & 1 & 2.9 & Temporal Cortex & 3 & 12.5 \\
\hline Occipital Cortex & 1 & 2.5 & Temporal Cortex & 1 & 2.9 & Occipital Cortex & 2 & 8.3 \\
\hline Insular Cortex & 1 & 2.5 & & & & & & \\
\hline Subcortical & 1 & 2.5 & & & & & & \\
\hline Total & 40 & 100. & Total & 35 & 100. & Total & 24 & 100 . \\
\hline
\end{tabular}

$* 8$ Primary Neural Regions. Bold $=$ Top tier; Ital $=2^{\text {nd }}$ tier; Plain text $=$ Bottom tier.

\section{Interpersonal}

The interpersonal literature review included 61 studies, identifying 93 citations of primary neural regions and 131 citations of sub-regions. The core skill units for interpersonal intelligence include Social Perception, Interpersonal Understanding, Social Effectiveness and Leadership (Tables 1 and 2, Section A) (Adolphs, 2009; Decety, Skelly \& Kiehl, 2013).

\section{Primary Regions}

Results from the analysis of the primary neural regions for the interpersonal and three skill units are displayed in Table 2, section A. The fourth skill unit - Social Effectiveness - is not included due to a paucity of neural citations. There are two dominant primary regions for the whole interpersonal group - frontal and temporal with cingulate and parietal of secondary importance (Supplemental Information B6). The Leadership skill unit most resembles the whole group with the same top four regions as their highest. Interpersonal Understanding differs from the whole group in the dominance of frontal (17 cites, $68 \%$ of total cites) and many fewer citations for only three other regions. Social Perception is also unique with temporal cortex as its highest (14 cites, 45\%) followed by three other regions with many fewer citations that are tied (4 cites, $13 \%$ each). 


\section{Sub-Regions}

The complete list of sub-regions for the whole interpersonal group is available in Supplemental Information B7. The highest ten sub-regions from this list are displayed in SI-B7. The prefrontal cortex dominates the whole interpersonal group (32 cites, 24\%) and is also highest for the Understanding Others and Leadership skill units, however, there are many fewer citations for Social Perception (2 cites, 5\%). In contrast, Social Perception is dominated by the superior temporal sulcus ( 7 cites, $18 \%$ ) with a variety of other sub-regions having only a few citations each (e.g., prefrontal 2 cites, 5\%) (SI-B8)

There are four sub-regions in common to all three skill units - prefrontal, anterior cingulate, inferior frontal gyrus and amygdala - and a diverse array of sub-regions that are unique to each of the three units. Sub-regions unique to specific skill units and shared among units are listed in Fig. 1 and Supplemental Information B9.

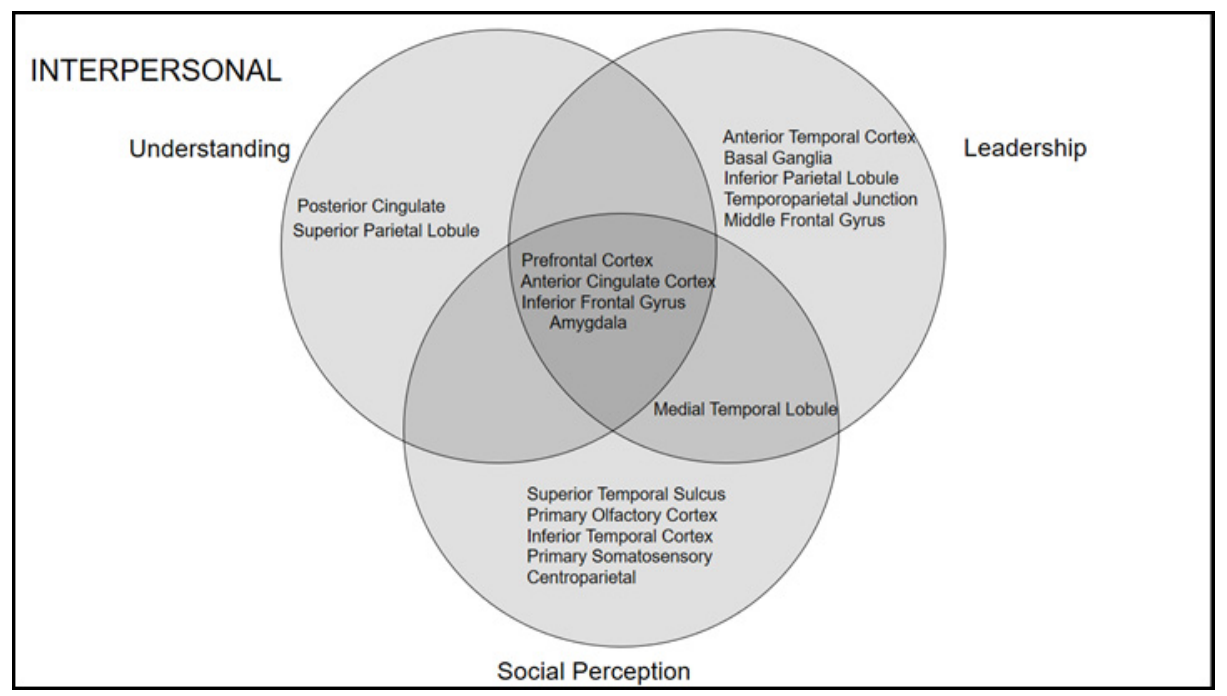

Figure 1. Interpersonal: Sub-Regions Unique and Common to Skill Units

Note. Three skill units are identified for interpersonal intelligence. Each unit has several neural regions unique to it along with several neural regions in common with other skill units. Four sub-regions are common to all three skill units.

\section{Multi-Region Networks}

The multi-region neural networks identified for the combined interpersonal groups are presented in SI- B10 and B11. Of note, for the whole interpersonal group are the highest two multi-regions that are those closely identified with social understanding and empathy: temporoparietal junction and the mirror neuron system.

A comparison among the three skill unit groups (Supplemental B11) reveals that the Social Perception group has the largest number of multi-region citations ( 7 cites vs. 3 cites and 2 cites). The two highest multi-regions are the sensorimotor cortex ( 2 cites) and the mirror neuron system ( 2 cites). Only the temporoparietal junction is common to all three units.

\section{Summary}

In summary (see Supplemental Information C55) the interpersonal group as a whole is dominated by the frontal and temporal regions $(69 \%)$, followed by several sub-regions: prefrontal cortex $(24 \%)$, dorsolateral prefrontal $(9 \%)$ and posterior orbitofrontal; superior temporal sulcus (6\%), hippocampus (3\%) and fusiform face area.

The Understanding People unit is most associated with the frontal and cingulate regions with $88 \%$ of the citations. Secondary analyses more specifically identified that the prefrontal cortex $(56 \%)$ and anterior cingulate cortex (16\%) accounted for a majority of sub-region citations. A third level analysis revealed the importance of the orbitofrontal and Brocas Area regions. The Leadership unit has a tie between the frontal and temporal regions $(8 \%)$ as its highest primary regions followed by several frontal sub-regions: prefrontal (19\%), medial prefrontal and Brocas Area; and several temporal sub-regions: superior temporal sulcus (18\%), posterior superior temporal (7\%) and fusiform face area. The Social Perception unit is dominated by the temporal region (45\%) followed by sub-regions: superior temporal sulcus (18\%), posterior superior temporal (7\%) and fusiform face area. 
Overall, the highest primary regions for the three skill units typically include both frontal and temporal regions with variability among the primary regions with lesser values. Each skill unit has its own unique sub-region pattern while having four sub-regions in common. Understanding has two sub-regions unique to it while both Leadership and Social Perception have five sub-regions that are not shared with either of the other two skill units.

\section{Intrapersonal}

The intrapersonal literature review included 101 studies, identifying 253 citations of neural primary and 437 sub-regions. The core cognitive units for intrapersonal intelligence include Self-Awareness, Self-Regulation, Executive Functions, and Self-Other management (Table 1, columns $3 \&$ 8, Table 2, section B) (Damasio, 2003; Northoff, et al, 2006).

\section{Primary Regions}

Results from the analysis of the primary neural regions for intrapersonal and three skill unit groups are displayed in Table 2, section B. The fourth skill unit - Self-Other Management -- is not included due to a paucity of neural citations. The frontal region dominates the intrapersonal group as a whole (100 cites, $40 \%)$ as well as for all three skill units (Supplemental B13 and Table 2, section B). This is particularly noticeable for Executive Functions where frontal accounts for $50 \%$ of the citations and there are many fewer citations for the remaining four other regions. Executive Functions group is also unique because there are no citations for temporal cortex while it is second highest for the other two skill units and the group as a whole. The primary region patterns for Self-Awareness and Self-Regulation are very similar to each other with Self-Awareness nearly identical to the group as a whole: frontal, temporal and cingulate are three highest cited regions (Table 2, section B).

\section{Sub-Regions}

The complete list of sub-regions for the whole intrapersonal group is presented in Supplemental B19. The highest ten sub-regions from the whole list are displayed in Supplemental B14. The sub-region comparisons table for the three skill units is presented in Supplemental B15. The prefrontal cortex dominates the whole intrapersonal group ( 81 cites, 18\%) and is also highest for all three skill units. This is followed by the anterior cingulate cortex that is second highest for Self-Awareness and Self-Regulation and third for Executive Functions. Unique to Executive Functions is the motor cortex as its second highest. Unique to Self-Regulation is the amygdala as its second highest in contrast to Self-Awareness where it is in last place and it is missing from list of sub-regions for Executive Functions.

There are three sub-regions in common to all three skill units - prefrontal, anterior cingulate and basal ganglia and a diverse array of sub-regions that are unique to each of the three units. Sub-regions unique to specific skill units and shared among units are listed in Fig. 2 and Supplemental Information B16.

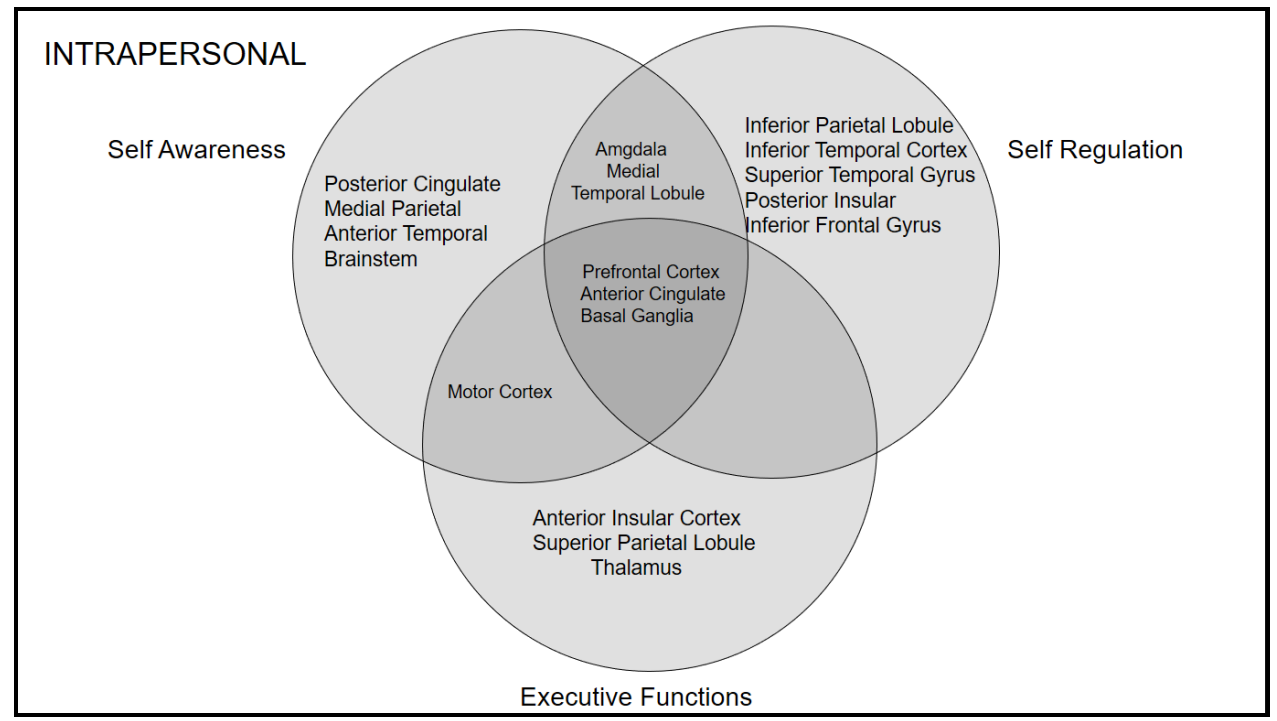

Figure 2. Intrapersonal: Sub-Regions Unique and Common Among Skill Units.

Note. Three skill units are identified for intrapersonal intelligence. Each unit has several neural regions unique to it along with several neural regions in common with other skill units. Three sub-regions are common to all three skill units. 


\section{Multi-Region Networks}

The multi-region neural networks identified for the combined intrapersonal groups are presented in Supplemental B17. Of note for the whole intrapersonal group are the highest three multi-regions that are closely identified with self-understanding and management: default mode network, cortical-midline system, and frontal executive network.

A comparison among the three skill unit groups (Supplemental B18) reveals the default mode network is highest for Self-Awareness and frontal executive network is highest for Self-Regulation. There are no multi-regions cited for Executive Functions and no multi-regions common to all three units.

\section{Summary}

In summary (see Supplemental Information C56) intrapersonal group as a whole is dominated by the frontal region $(39 \%)$, followed by several frontal sub-regions: prefrontal cortex (31\%), dorsomedial prefrontal (7\%) and ventromedial orbitofrontal cortex.

The Self-Awareness unit is nearly identical to the intrapersonal group as a whole for both primary and sub-region arrays. The frontal (37\%), temporal (18\%) and cingulate (16\%) primary regions dominate followed by associated sub-regions: prefrontal cortex, medial / anterior temporal and anterior / posterior cingulate. Level three sub-regions are also similar to those cited for the whole group: ventromedial orbitofrontal, parahippocampus, and ventral striatum. The Self-Regulation unit is only dominated by the frontal cortex (30\%) followed by sub-regions prefrontal (17\%), lateral prefrontal and (unique to Self-Regulation) Broca's Area and the fusiform gyrus. The Executive Functions unit is dominated by the frontal cortex $(50 \%)$ and prefrontal and motor cortex sub-region followed by orbitofrontal and pre-supplementary motor area. Unique to Executive Functions are cited the precuneus and striatum.

Overall, two skill units have the same five highest primary regions with frontal and temporal in the top two positions. Executive Functions is unique because temporal is missing from its list altogether and frontal dominates with all other regions having much smaller values. Each skill unit has its own unique sub-region pattern while having three sub-regions in common. Self-Awareness has four sub-regions unique to it while Self-Regulation has five sub-regions unique and Executive Functions has three sub-regions that are not shared with either of the other two skill units.

\section{Linguistic}

The linguistic literature review included 37 studies, identifying 156 citations of primary neural regions and 93 sub-regions. The core cognitive units for linguistic intelligence includes Reading, Writing, Speech and Other Language functions (McCandliss \& Noble, 2003; Price, 2012). (Table 1, columns 3 \& 8; Table 2, section C).

\section{Primary Regions}

Results from the analysis of the primary neural regions for the three skill unit groups are displayed in Table 2, section C. The fourth and fifth skill units -Multi-Modal and Other Language functions - are not included due to inadequate definitional clarity. The temporal cortex dominates the linguistic group as a whole (see SI- B20 (51 cites, $33 \%$ ) as well as two of the three skill units. This is particularly noticeable for the Speech unit (12 cites, $52 \%)$ and less so for Reading $(13,34 \%)$ but temporal cortex is tied for third place with Subcortical for Writing (5 cites, $12 \%$ ). There are only four sub-regions for Speech following temporal that are much fewer in number (ranging from $1-5$ ). The Reading skill unit differs from the other two units because it is dominated by three primary regions - temporal, frontal and parietal. Writing is dominated by frontal and occipital (50\%) which is unique because occipital is low on the list for Reading and missing from the Speech unit. Parietal cortex is highest for Reading ( 8 cites, $21 \%$ ) and lower for Writing ( 4 cites, $10 \%$ ) and Speech ( 4 cites, $17 \%$ ) (see Table 2, section C).

\section{Sub-Regions}

The complete list of sub-regions for the whole linguistic group is presented in Supplemental Information B25 and the highest 10 sub-regions are listed below in SI-B21. The sub-region comparisons table for the three skill unit groups are presented in SI-B22.

The inferior frontal gyrus dominates the linguistic group as a whole (16 cites, 9\%) and the Reading skill unit (6 cites, 13\%) (see SI-B21). There are distinct differences among the three skill units. Both Speech and Writing are dominated by two sub-regions that are different from each other: Speech = inferior parietal lobule and superior temporal sulcus; Writing = prefrontal and motor cortex. The highest sub-region for Reading is the inferior frontal gyrus $(6$ cites, $13 \%)$ followed by many other sub-regions at lower values (ranging $1-4)$. The prefrontal cortex is 
second highest for the whole linguistic group but missing from Speech and Reading and tied for highest for Writing (5 cites, $12 \%$ ) (see SI-B22).

There are two sub-regions common to all three skill units - motor cortex and inferior frontal gyrus - and a diverse array of sub-regions unique to each unit (see Fig. 3 and Supplemental Information B23).

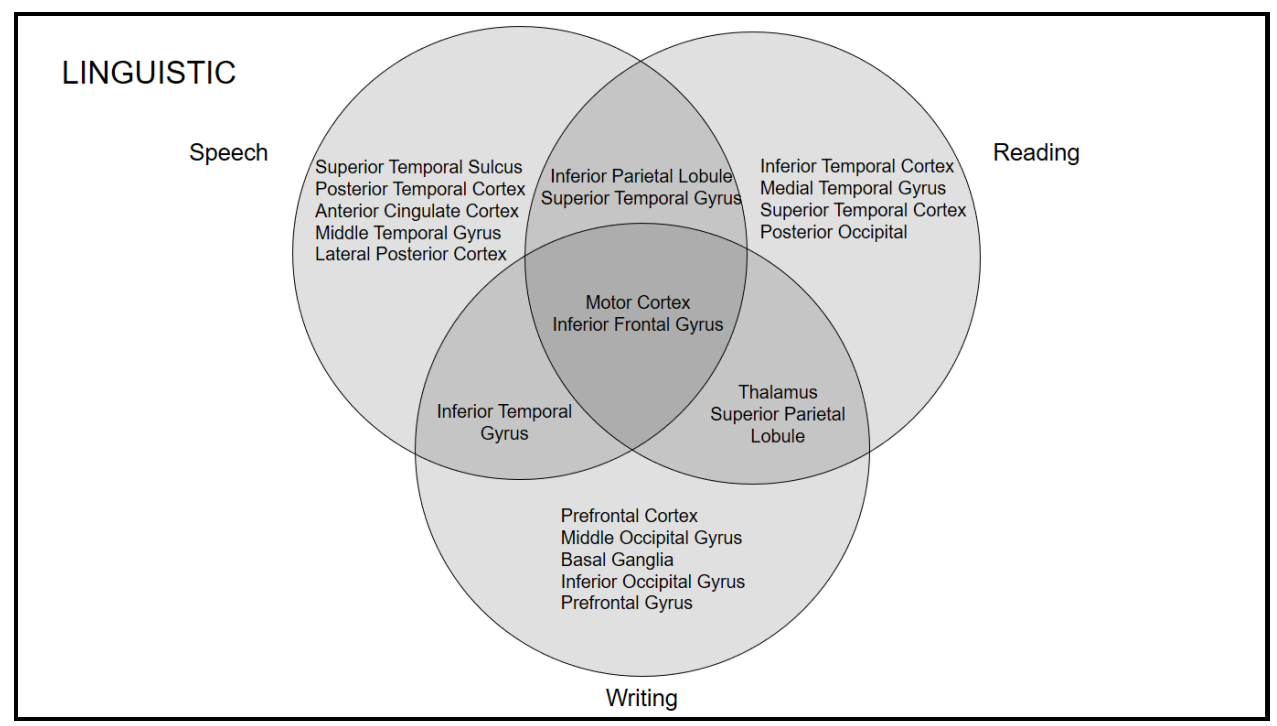

Figure 3. Linguistic: Sub-Regions Unique and Common Among Skill Units.

Note. Three skill units are identified for linguistic intelligence. Each unit has several neural regions unique to it along with several neural regions in common with other skill units. Two sub-regions are common to all three skill units.

\section{Multi-Regions}

The top two multi-region neural networks for the whole group are those that are most often associated with both basic language processing and reading/writing - occipitotemporal cortex and language areas (Supplemental B24).

The multi-region network comparisons among the skill unit groups reveals several differences (Supplemental B25). There are three multi-regions cited seven times for Reading; two regions for Speech and no multi-regions cited for Writing. Reading is noted for the multi-regions involving the temporal cortex (occipitotemporal, parietotemporal) while Speech is associated with the frontoparietal network and language areas.

\section{Summary}

In summary, (see Supplemental Information C57) linguistic intelligence for the combined group is associated most strongly with the temporal (51 cites, 33\%), frontal (44 cites, $28 \%$ ) and parietal (24 cites, $15 \%$ ) primary regions. Temporal sub-regions identified include inferior temporal, fusiform gyrus and visual word form area. Frontal sub-regions include inferior frontal gyrus, posterior inferior frontal gyrus and Brocas Area. Parietal sub-regions include inferior parietal lobule, angular gyrus and precuneus.

The Reading skill unit has its highest primary regions nearly identical to those of the whole group described above. Many of the same sub-regions are also included. Writing skill unit is dominated by the frontal (13 cites, $31 \%$ ) and occipital (8 cites, 19\%) regions. Sub-regions within the frontal cortex include prefrontal, motor cortex, dorsolateral PFC, Brocas Area and the orbitofrontal gyrus. Speech has the temporal cortex as its dominant (12 cites, $52 \%$ ) with related sub-regions: superior temporal sulcus, Wernickes Area, and the visual word form area.

Overall, two skill units have temporal, frontal and parietal as their highest while it is in fourth place for the Writing unit. Writing is also different with occipital in second place and it is of much less importance to the other skill units. Each skill unit has its own unique sub-region pattern while having two sub-regions in common. Reading has four sub-regions unique to it while both Writing and Speech have five sub-regions that are not shared with either of the other two skill units. 


\section{Logical-mathematical}

The logical-mathematical literature review included 32 studies, identifying 99 citations of primary regions and 131 sub-regions citations. The core cognitive units for logical-math intelligence include Mathematical Reasoning and Logical Reasoning, and $g$ (General Intelligence) (Table 2, columns 3 \& 8) (Barbey \& Barsalou, 2009; Dehaene, Molko, Cohen \& Wilson, 2004; Duncan, et al, 2000).

\section{Primary Regions}

Results from the analysis of the primary neural regions for whole Logical-mathematical group and the three skill unit groups are displayed in Table 2, section D). There are two dominant primary regions tied for first place for the whole Logical-math group - frontal and parietal (32 cites, 27\%) and the temporal region is in third place at 19 cites (18\%), (Supplemental B27). The frontal region is among the highest for all skill unit groups. General Intelligence $(\mathrm{g})$ most closely resembles the whole group in its pattern of primary regions. Mathematical Reasoning differs from the whole group in the dominance of the parietal region (18 cites, 51\%) while Logical Reasoning has the temporal region as its highest (15 cites, 38\%) at a much higher level than all the other groups. The parietal region is in first place for $g$ and Math Reasoning but is in third place for Logical Reasoning (Table 2, section D).

\section{Sub-Regions}

The complete list of sub-regions for the whole Logical-math group is available in Supplemental Information B33. The highest ten sub-regions from the whole list are displayed in SI-B28. The sub-region comparisons table for the three-skill unit group are presented in SI-B29.

The prefrontal cortex dominates the whole Logical-math group (32 cites, 24\%) (SI-B33). The prefrontal cortex is also highest for Logical Reasoning (7 cites, 16\%) and in second place for Math Reasoning (5 cites, 14\%) but missing entirely from the $g$ skill unit. The $g$ skill unit is unique for the lack of a single dominate sub-region but instead there are five sub-regions with only two citations each from the frontal, parietal and temporal lobes (Table 2, section D).

There are two sub-regions in common to all three skill units - inferior parietal cortex, inferior frontal gyrus -and several sub-regions that are unique to each of the skill units. The intraparietal sulcus is unique to and highest for Math Reasoning (8 cites, 23\%) and missing from the other two skill units. Sub-regions unique to specific skill units and shared among units are listed in Fig. 4 and Supplemental Information B30.

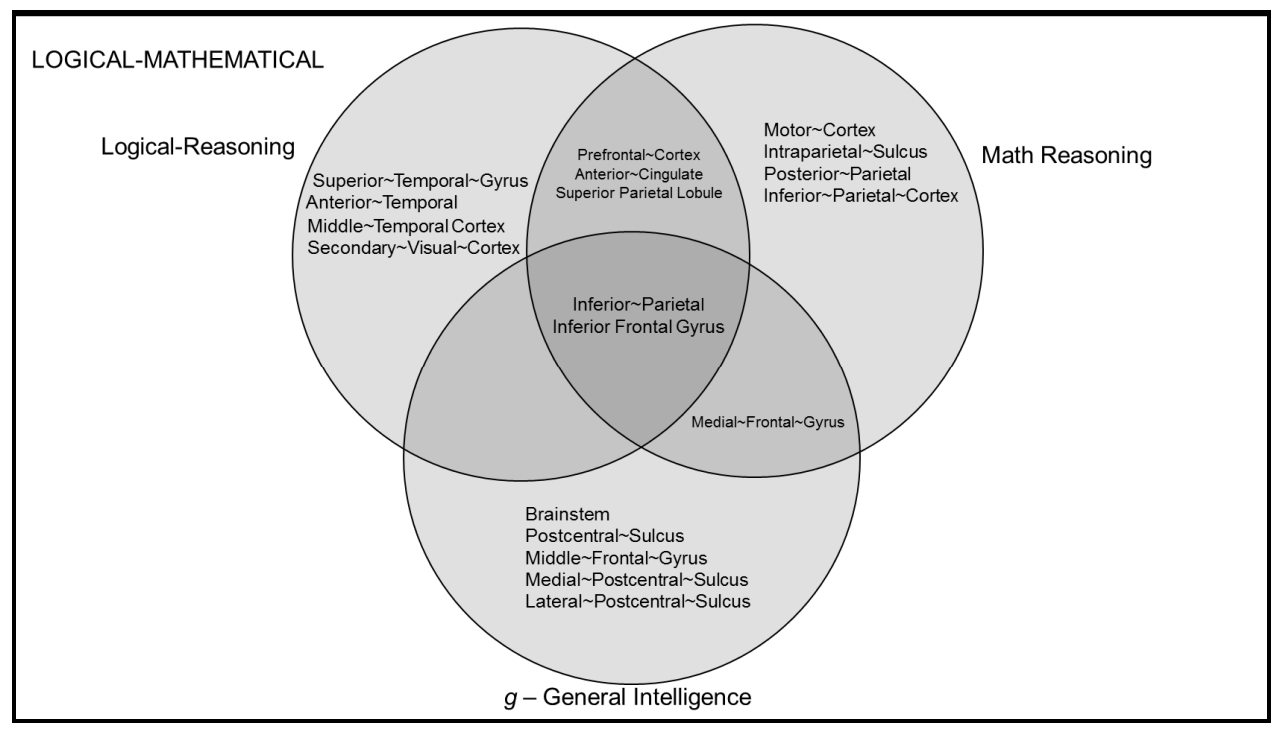

Figure 4. Logical-Mathematical: Sub-Regions Unique and Common Among Skill Units.

Note. Three skill units are identified for logical-mathematical intelligence. Each unit has several neural regions unique to it along with several neural regions in common with other skill units. Two sub-regions are common to all three skill units. 


\section{Multi-Regions}

The multi-region neural networks identified for the combined logical-math groups are presented in Supplemental Information B31 and B32. Of note, there are five multi-regions with single citations for the whole group including frontoparietal and frontotemporal cortices.

A comparison among the three skill unit groups (Supplemental B32) reveals that only Logical Reasoning has more than one multi-region cited. The four multi-regions cited are very similar to those cited for the whole Logical-math group. There are no multi-regions cited for Math Reasoning and only one for $g$, sylvian fissure.

\section{Summary}

In summary, (see Supplemental Information C58) the logical-math group as a whole is dominated by the frontal and parietal regions (tied at 32 cites, $31 \%$ ) followed by several sub-regions: prefrontal, posterior inferior frontal and Brocas Area.

The Logical Reasoning unit is dominated by the temporal and frontal cortices (70\%). Secondary analyses of temporal sub-regions for Logical Reasoning more specifically identified the medial temporal and parahippocampal gyrus. Sub-regions within the frontal region include the prefrontal and dorsolateral prefrontal and Brocas Area. Mathematical Reasoning is associated with the parietal cortex (18 cites, 51\%) followed by the intraparietal sulcus, angular gyrus and precuneus. The frontal cortex is of secondary importance with sub-regions- prefrontal, posterior inferior front and Brocas Area. General intelligence $(g)$ has the parietal and frontal tied as its highest primary regions ( 8 cites, $32 \%$ ). Secondary analyses of the parietal region identified the inferior parietal lobule, supramarginal gyrus and anterior supramarginal gyrus. Sub-regions identified within the frontal region include medial / lateral postcentral lobules and the posterior inferior frontal.

Overall, two skill units have the same two highest primary regions (parietal and frontal) while temporal is uniquely highest for Logical Reasoning. General Intelligence is unique because the cingulate cortex is missing from its list altogether while it is in third and fourth place for the other two units. Frontal is in second place for all three skill units. Each skill unit has its own unique sub-region pattern while having two sub-regions in common. General Intelligence has five sub-regions unique to it while both Math Reasoning and Logical Reasoning have four sub-regions each that are not shared with either of the other two skill units.

Table 3. Primary Regions Skills Unit Comparisons: Visual-spatial, Kinesthetic \& Musical

\section{A $\quad$ Visual-Spatial: Primary Region Skill Unit Comparisons}

\begin{tabular}{|c|c|c|c|c|c|c|c|c|c|c|c|}
\hline \multicolumn{3}{|c|}{ Spatial Cognition } & \multicolumn{3}{|l|}{ Insight-Intuition } & \multicolumn{3}{|l|}{ Visual Arts } & \multicolumn{3}{|c|}{ Working with Objects } \\
\hline Regions & ct & $\%$ & Regions & ct & $\%$ & Regions & ct & $\%$ & Regions & ct & $\%$ \\
\hline Frontal Cortex & 43 & 35. & Subcortical & 10 & 31. & $\begin{array}{l}\text { Frontal } \\
\text { Cortex }\end{array}$ & 12 & 48. & $\begin{array}{l}\text { Parietal } \\
\text { Cortex }\end{array}$ & 10 & 43. \\
\hline Parietal Cortex & 25 & 20. & Frontal Cortex & 10 & 31. & $\begin{array}{l}\text { Parietal } \\
\text { Cortex }\end{array}$ & 6 & 24. & $\begin{array}{l}\text { Frontal } \\
\text { Cortex }\end{array}$ & 7 & 30. \\
\hline $\begin{array}{l}\text { Temporal } \\
\text { Cortex }\end{array}$ & 20 & 16. & Parietal Cortex & 4 & 12. & Subcortical & 4 & 16. & $\begin{array}{l}\text { Occipital } \\
\text { Cortex }\end{array}$ & 3 & 13. \\
\hline Occipital Cortex & 16 & 13. & $\begin{array}{l}\text { Cingulate } \\
\text { Cortex }\end{array}$ & 3 & 9. & $\begin{array}{l}\text { Temporal } \\
\text { Cortex }\end{array}$ & 1 & 4. & $\begin{array}{l}\text { Temporal } \\
\text { Cortex }\end{array}$ & 3 & 13. \\
\hline Cerebellum & 5 & 4. & Cerebellum & 2 & 6. & $\begin{array}{l}\text { Occipital } \\
\text { Cortex }\end{array}$ & 1 & 4. & & & \\
\hline Subcortical & 5 & 4. & $\begin{array}{l}\text { Occipital } \\
\text { Cortex }\end{array}$ & 2 & 6. & $\begin{array}{l}\text { Cingulate } \\
\text { Corte }\end{array}$ & 1 & 4. & & & \\
\hline $\begin{array}{l}\text { Cingulate } \\
\text { Cortex }\end{array}$ & 4 & 3. & $\begin{array}{l}\text { Temporal } \\
\text { Cortex }\end{array}$ & 1 & 3. & & & & & & \\
\hline Insular Cortex & 2 & 1. & & & & & & & & & \\
\hline Total & 120 & 100 & Total & 32 & 100 & Total & 25 & 100 & Total & 23 & 100 \\
\hline
\end{tabular}


B $\quad$ Kinesthetic: Primary Region Skill Unit Comparisons

\begin{tabular}{|c|c|c|c|c|c|c|c|c|c|c|c|}
\hline \multicolumn{3}{|l|}{ Dexterity } & \multicolumn{3}{|l|}{ Whole Body } & \multicolumn{3}{|c|}{ Body Awareness } & \multicolumn{3}{|c|}{ Motor Cognition } \\
\hline Regions & ct & $\%$ & Regions & ct & $\%$ & Regions & ct & $\%$ & Regions & ct & $\%$ \\
\hline Frontal Cortex & 25 & 37. & Parietal Cortex & 17 & 34. & $\begin{array}{l}\text { Frontal } \\
\text { Cortex }\end{array}$ & 21 & 48 & $\begin{array}{l}\text { Frontal } \\
\text { Cortex }\end{array}$ & 11 & 55. \\
\hline Temporal Cortex & 11 & 16. & Frontal Cortex & 16 & 32. & $\begin{array}{l}\text { Parietal } \\
\text { Cortex }\end{array}$ & 10 & 23 & $\begin{array}{l}\text { Parietal } \\
\text { Cortx }\end{array}$ & 6 & 30 \\
\hline Parietal Cortex & 11 & 16. & Subcortical & 5 & 10. & Subcortical & 4 & 9 & $\begin{array}{l}\text { Cerebellu } \\
\mathrm{m}\end{array}$ & 3 & 15 \\
\hline Cerebellum & 7 & 10 & Cerebellum & 5 & 10. & $\begin{array}{l}\text { Insular } \\
\text { Cortex }\end{array}$ & 4 & 9. & & & \\
\hline Subcortical & 7 & 10 & Occipital Cortex & 3 & 6. & $\begin{array}{l}\text { Cingulate } \\
\text { Cortex }\end{array}$ & 2 & 4. & & & \\
\hline Cingulate Cortex & 4 & 6. & Temporal Cortex & 2 & 4. & Cerebellum & 2 & 4. & & & \\
\hline \multirow[t]{2}{*}{ Insular Cortex } & 2 & 3. & Cingulate Cortex & 1 & 2. & & & & & & \\
\hline & & & Brainstem & 1 & 2. & & & & & & \\
\hline Total & 67 & 100 & Total & 50 & 100 & Total & 43 & 100 & Total & 20 & $\begin{array}{l}10 \\
0\end{array}$ \\
\hline
\end{tabular}

C $\quad$ Musical: Primary Region Skill Unit Comparisons

\begin{tabular}{|c|c|c|c|c|c|c|c|c|c|c|c|}
\hline \multicolumn{3}{|l|}{ Production } & \multicolumn{3}{|l|}{ Perception } & \multicolumn{3}{|l|}{ Cognition } & \multicolumn{3}{|c|}{ Melody-Pitch-Rhythm } \\
\hline Regions & ct & $\%$ & Regions & ct & $\%$ & Regions & $\mathrm{ct}$ & $\%$ & Regions & $\mathrm{ct}$ & $\%$ \\
\hline Frontal Cortex & 95 & 43 & $\begin{array}{l}\text { Frontal } \\
\text { Cortex }\end{array}$ & 21 & 32 & $\begin{array}{l}\text { Frontal } \\
\text { Cortex }\end{array}$ & 10 & 35 & $\begin{array}{l}\text { Temporal } \\
\text { Cortex }\end{array}$ & 8 & 36 \\
\hline $\begin{array}{l}\text { Temporal } \\
\text { Cortex }\end{array}$ & 43 & 19 & $\begin{array}{l}\text { Temporal } \\
\text { Cortex }\end{array}$ & 20 & 31 & $\begin{array}{l}\text { Temporal } \\
\text { Cortex }\end{array}$ & 7 & 25 & $\begin{array}{l}\text { Parietal } \\
\text { Cortex }\end{array}$ & 7 & 31 \\
\hline Parietal Cortex & 23 & 10 & Cerebellum & 8 & 12 & $\begin{array}{l}\text { Parietal } \\
\text { Cortex }\end{array}$ & 6 & 21 & $\begin{array}{l}\text { Frontal } \\
\text { Cortex }\end{array}$ & 4 & 18 \\
\hline Subcortical & 18 & 8 & Subcortical & 8 & 12 & Cerebellum & 3 & 10 & $\begin{array}{l}\text { Insular } \\
\text { Cortex }\end{array}$ & 1 & 4 \\
\hline Cerebellum & 16 & 7 & Parietal Cortex & 6 & 9 & $\begin{array}{l}\text { Occipital } \\
\text { Cortex }\end{array}$ & 1 & 3 & $\begin{array}{l}\text { Occipital } \\
\text { Cortex }\end{array}$ & 1 & 4 \\
\hline Cingulate Cortex & 9 & 4 & Insular Cortex & 1 & 1 & Subcortical & 1 & 3 & Cerebellum & 1 & 4 \\
\hline Insular Cortex & 8 & 3 & & & & & & & & & \\
\hline Occipital Cortex & 5 & 2 & & & & & & & & & \\
\hline Total & 217 & $\begin{array}{l}10 \\
0\end{array}$ & & 64 & 100 & Total & 28 & $\begin{array}{l}10 \\
0\end{array}$ & Total & 22 & 100 \\
\hline
\end{tabular}

$* 8$ Primary Neural Regions. Bold $=$ Top tier; Ital $=2^{\text {nd }}$ tier; Plain text $=$ Bottom tier.

\section{Visual-Spatial}

The visual-spatial literature review included 49 studies, identifying 200 citations of primary and 308 sub-regions. The core cognitive units for visual-spatial intelligence includes Spatial Cognition, Insight-Intuition, Visual Arts, and Working with Objects (Tables 1 and 3, section A) (Aziz-Zadeh, Liew \& Dandekar, 2013; Cui, 2007; Qiu, et al, 2008). 


\section{Primary Regions}

Results from the analysis of the primary neural regions for the visual-spatial and four skill units are displayed in Table 3, section A. There are two dominant primary regions for the whole visual-spatial group accounting for $59 \%$ of all citations- frontal (36\%) and parietal (23\%) (Supplemental B34). The Spatial Cognition unit most resembles the whole group with the same top four regions with generally the same values. The Insight-Intuition unit differs the most from the whole group with Subcortical regions as its highest (10 cites, 31\%) and tied with frontal. Parietal is in its third position at a much lower value (12\%) than either of the other units ( $20 \%$ vs. $43 \%)$. The Visual Arts unit has the frontal region in first place at a value higher than all other skill units ( $48 \%$ vs. $30 \%$ vs. $35 \%$ ) (Table 3, section A).

\section{Sub-Regions}

The complete list of sub-regions for the whole visual-spatial group is presented in Supplemental Information B40. The sub-region comparisons table for the four skill units is presented in Supplemental Information B36.

The motor and prefrontal cortices dominate the whole visual-spatial group (23 cites, 5\%; 21 cites, 5\%, respectively) (SI-B35). Of secondary importance are three sub-regions - basal ganglia (13 cites), premotor (13 cites) and superior parietal lobule (12 cites).

The prefrontal and motor cortices are the highest for the Spatial Cognition and Visual Arts sub-regions. The basal ganglia and prefrontal are highest for Insight while the motor cortex and intraparietal sulcus are the highest for Working with Objects. Spatial Cognition and Working with Objects share the intraparietal sulcus and inferior temporal cortex. The inferior parietal lobule is common to three of the four skill units: Spatial Cognition, Visual Arts and Working with Objects (Table 3, section A).

There are two sub-regions common to all four skill units: motor cortex and superior parietal lobule and several sub-regions that are unique to and shared by two or more skill units. See Fig. 5 and Supplemental Information B37.

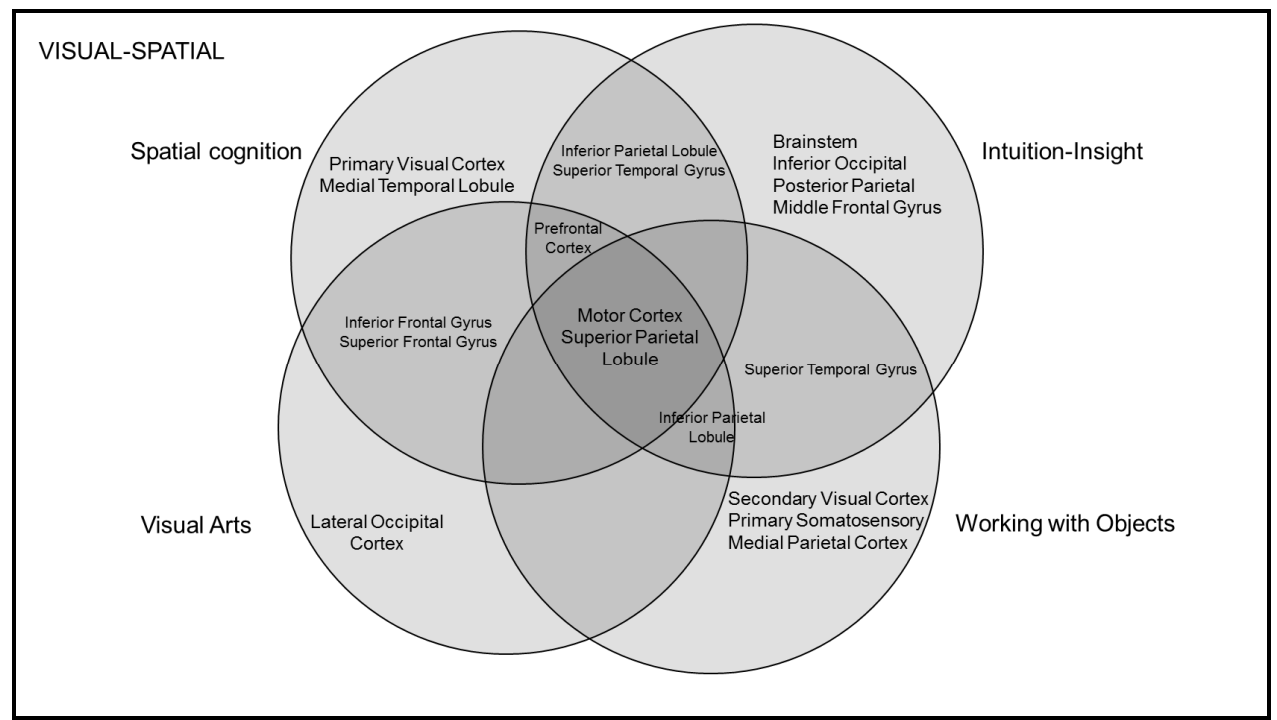

Figure 5. Visual-Spatial: Sub-Regions Unique and Common Among Skill Units

Note. Four skill units are identified for visual-spatial intelligence. Each unit has several neural regions unique to it along with several neural regions in common with other skill units. Three sub-regions are common to all four skill units.

\section{Multi-Regions}

The multi-region neural networks identified for the whole visual-spatial sample and skill units are presented in Supplemental Information B38 and B39. Of note are three occipital and parietal networks and the mirror neuron system. These are same as is evident for the Spatial Cognition and Insight-Intuition skill units.

\section{Summary}

In summary, (see Supplemental Information C59) for the combined groups visual-spatial intelligence is strongly associated with two primary regions- frontal (72 cites, 36\%) and parietal (45 cites, 23\%). The next strongest 
primary regions are temporal and occipital. The remaining four regions are of much lesser importance. The highest frontal sub-regions are the motor and prefrontal cortices followed by the third level premotor and dorsolateral prefrontal cortex. The sub-regions of note within the parietal cortex are superior parietal lobule, precuneus and posterior precuneus.

The Spatial Cognition skill unit shares the same primary regions as the whole group - frontal and parietal along with the same frontal and parietal sub-regions, but includes the supramarginal gyrus. The Insight-Intuition skill group is uniquely identified with the Subcortical primary region followed by basal ganglia, striatum/midbrain and the dorsal striatum. The frontal cortex is its second highest primary region including the prefrontal and dorsolateral prefrontal sub-regions. The Visual Arts skill unit has the highest percentage of frontal cortex citations (12, cites, $48 \%$ with numerous frontal sub-regions including prefrontal, premotor, dorsolateral PFC and posterior dorsolateral PFC. The Working with Objects skill unit is unique for having parietal cortex as its highest (10 cites, 44\%) followed by its sub-regions: intraparietal sulcus, anterior intraparietal and angular gyrus. Frontal cortex is its second highest primary region including the motor and premotor cortices and dorsal premotor gyrus.

Overall, the highest regions for three skill units include frontal and parietal as their highest primary regions with occipital and temporal as second tier importance. Insight-Intuition is unique with subcortical and frontal tied for first place and five other regions of lesser importance. Each skill unit has its own unique sub-region pattern while having three sub-regions in common. Insight-Intuition has four sub-regions unique to it. Working with Objects has three unique sub-regions while both Spatial Cognition and Visual Arts have two sub-regions that are not shared with either of the other two skill units. Several skill units each have two or three sub-regions that are shared with one other skill unit.

\section{Kinesthetic}

The kinesthetic literature review included 60 studies, identifying 338 citations of primary neural regions and 551 sub-regions. The core skill units for kinesthetic intelligence includes Motor Cognition, Dexterity, Whole Body Movement, Body Awareness, and Other Movements (Brown, Martinez \& Parsons, 2006; Jantzen, Steinberg \& Kelso, 2008). (see Tables 2 and 3, section B).

\section{Primary Regions}

Results from the analysis of the primary neural regions for the whole group and four skill units are displayed in Table 3, section B and Supplemental B41. The fifth skill unit - Symbolic Movements - is not included due to inadequate definitional clarity.

The frontal and parietal regions dominate the group as a whole (97 cites, $42 \%$; 53 cites, $23 \%$, respectively). These are followed by three regions of secondary importance (cerebellum, 23; subcortical, 21 and temporal 17 cites each) associated with kinesthetic intelligence (Table 3, section B). Both frontal and parietal regions are in either first or second place for all skill units, however, significant differences are evident thereafter. There are only a total of three primary regions for the Motor Cognition unit where cerebellum is in third place. Cerebellum is tied with Subcortical as of secondary importance for the Dexterity and Whole Body units. Uniquely, the Cerebellum is in last place for the Body Awareness unit. Unique to the Dexterity unit is the presence of temporal cortex in second place while it is much lower for Whole Body and not present for Body Awareness and Motor Cognition.

\section{Sub-Regions}

The complete list of sub-regions for the whole kinesthetic group is presented in Supplemental Information B47. The sub-region comparison table for the three skill unit groups is presented in Supplemental Information B43.

The Motor Cortex (69 cites, 16\%) dominates the whole kinesthetic group and is also highest for all four skill units (SI-B47). Sub-region citation values for all four units are much lower thereafter. Of note, Dexterity has the superior temporal gyrus and basal ganglia of secondary importance. There are four sub-regions tied as secondary importance for the Whole Body skill unit including the superior temporal gyrus and basal ganglia. Basal ganglia and posterior parietal cortex are in secondary positions for Body Awareness. The prefrontal cortex is second highest following Motor Cortex for the Motor Cognition skill unit (SI-B43).

There are two sub-regions in common to all four skill units - motor cortex, primary somatosensory cortex- and several sub-regions that are unique to each of the four units. Sub-regions unique to specific skill units and shared among units are listed in Fig. 6. There are a variety of sub-regions in common to two or three units described in Fig. 6 including these examples: Whole Body and Dexterity = anterior cerebellum and thalamus; Motor 
Cognition and Whole Body $=$ posterior parietal cortex. Additional information is presented in Supplemental Information B44.

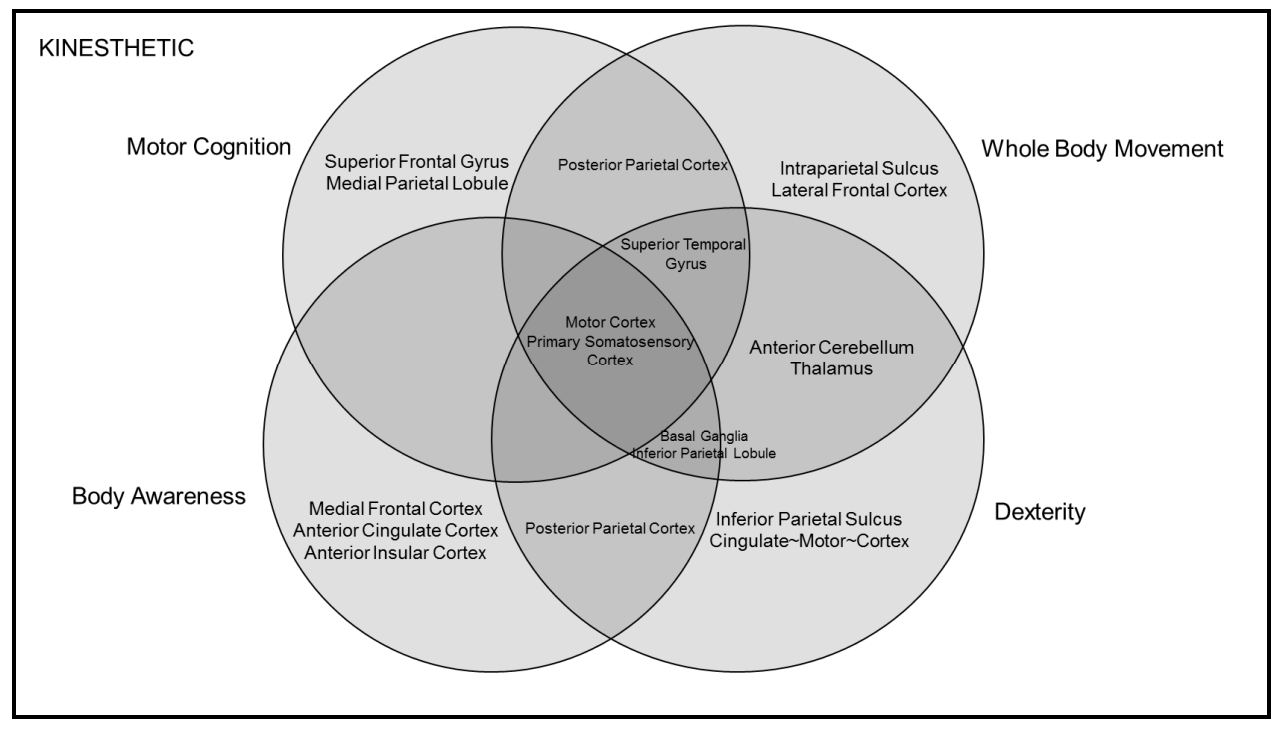

Figure 6. Kinesthetic: Sub-Regions Unique and Common Among Skill Units.

Note. Four skill units are identified for kinesthetic intelligence. Each unit has several neural regions unique to it along with several neural regions in common with other skill units. Two sub-regions are common to all three skill units.

\section{Multi-Regions}

The multi-region neural networks identified for the whole kinesthetic sample are presented in Supplemental Information B45 and B46. The top three networks - mirror neuron, frontoparietal and limbic -- are not specifically focused on brain regions most often associated with physical movements but instead pertain to interpersonal understanding, external focused attention, and emotions. However, there are single citations for four networks that do deal with body movement: cerebellothalamic, sensorimotor cortex, audiovisual motor and pontocerebellar.

\section{Summary}

In summary, (see Supplemental Information C60) the kinesthetic group as a whole is dominated by the frontal (97 cites, $42 \%)$ and parietal (53 cites, $23 \%$ ) regions, followed by several sub-regions: motor cortex (27\%), primary motor $(25 \%)$ and dorsal / ventral premotor.

The Dexterity unit is most associated with the frontal cortex (37\%) followed by the temporal and parietal cortices (tied at $16 \%$ each). Secondary analyses more specifically identified motor, primary motor and dorsal premotor sub-regions. Within the parietal region the inferior parietal lobule is noted. The Whole Body Movement unit has nearly a tie between the frontal and parietal regions $32 \%$ and $34 \%$ ) as its highest primary regions followed by several frontal sub-regions: motor cortex (21\%), primary motor, SMA, and Brocas Area. Several parietal sub-regions are identified: Posterior / inferior parietal and the medial superior / posterior parietal. The Body Awareness unit is dominated by the same two primary regions: frontal (49\%) and to a lesser extent the parietal $(23 \%)$. Secondary analyses more specifically identified motor, primary motor, SMA and lateral premotor sub-regions. Within the parietal region, the posterior parietal cortex is noted. The Motor Cognition unit is also dominated by the frontal (55\%) and parietal cortices (30\%). Secondary analysis identified the motor and prefrontal sub-regions followed by the SMA and dorsal / ventral premotor regions. Sub-regions within the parietal cortex includes the medial / inferior parietal structures.

Overall, the highest primary regions for the three skill units typically include both frontal and parietal regions with variability among the primary regions with lesser values. Dexterity is unique for having the temporal cortex tied as second highest tied with parietal. Each skill unit has its own unique sub-region pattern while having two sub-regions in common. Body Awareness has three sub-regions unique to it while the remaining three skill units have only two sub-regions that are unique and are not shared with either of the other three units. 


\section{Musical}

The musical literature review included 77 studies, identifying 338 citations of primary regions and 551 sub-regions. The skill units for musical intelligence include Musical Production, Musical Perception, Musical Cognition, and Melody-Pitch-Rhythm (Tables 2 and 3, section C) (Basten, Hilger \& Fiebach, 2015; Gaser \& Schlaug, 2003).

\section{Primary Regions}

Results from the analysis of the primary neural regions for the whole musical group and four skill units are displayed in Tables 3, section C and SI-B48. There are two primary regions that dominate the whole musical group: frontal (132 cites, 39\%) and temporal (80 cites, 24\%). Of secondary importance are three regions: parietal (42 cites, 12\%), subcortical (28 cites, 9\%) and cerebellum (28 cites, 8\%) (SI-B48). The Cognition and Production skill units are very similar in their highest three regions - frontal, temporal and parietal -- and the same two regions of second level importance - subcortical and cerebellum. The Perception skill unit shares the same top primary regions is highest for the whole group - frontal and temporal - and the second level regions are also similar to the whole group (Table 3, section C).

The Melody-Pitch-Rhythm skill unit differs the most from the whole group as well as the other three skill units. The temporal and parietal regions are its two highest with frontal in third place at a much lower level (18\% vs. $35 \%, 32 \%$ and $43 \%$ ).

\section{Sub-Regions}

The complete list of sub-regions for the whole musical group is presented in Supplemental Information B54. The sub-region comparisons table for the four skill units is presented in Supplemental Information B50.

The motor cortex and superior temporal gyrus dominate the whole musical group (77 cites, 14\%; 48 cites, 9\%, respectively) and are also highest for three skill units- Production, Perception and Cognition. There are distinct differences in the overall sub-region patterns for the musical skill units. Motor cortex dominates the Production skill unit (55 cites, 22\%) while Perception is dominated by motor and superior temporal gyrus (tied at 17 cites, 26\%). The Musical Cognition unit has three sub-regions tied as its highest but at very low levels (4 cites, 14\%) motor cortex, inferior frontal gyrus and superior temporal cortex. The Melody-Pitch-Rhythm unit has two sub-regions tied as its highest also at low levels (3 cites, 13\%) - inferior parietal lobule and superior temporal cortex (SI-B50).

There are three sub-regions in common to all four skill units - motor cortex, superior temporal cortex, prefrontal gyrus and inferior parietal lobule - and a few sub-regions unique to each of the skill units. Sub-regions unique and shared among units are listed in Fig. 7 or Supplemental Information B51.

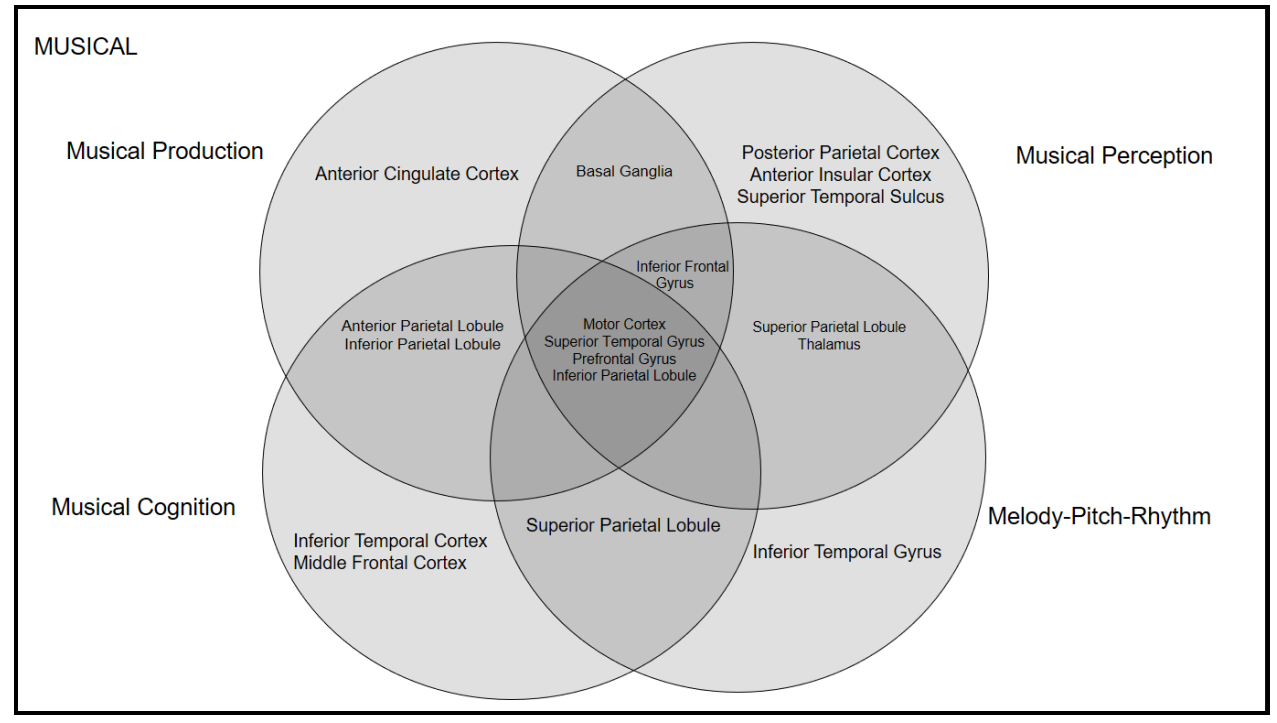

Figure 7. Musical: Sub-Regions Unique and Common Among Skill Units.

Note. Four skill units are identified for musical intelligence. Each unit has several neural regions unique to it along with several neural regions in common with other skill units. Four sub-regions are common to all four skill units. 


\section{Multi-Regions}

The multi-region neural networks identified for the whole musical sample are presented in Supplemental B52. It is noteworthy that there are many multi-regions cited including the language areas, mirror neuron system, corpus callosum and temporoparietal junction. This suggests that musical processing involves widespread patterns of cerebral activation.

Multi-regions cited for the four skill units are displayed in Supplemental Information B53. The multi-region list for the Musical Production skill unit is nearly identical to that of the whole musical group. It also stands in stark contrast to that of the other three skill units which have none or a few multi-regions cited. Of note, the Musical and Perception skill unit is associated with two multi-regions - mirror neuron and limbic systems. This is of interest because this skill unit includes the emotional aspects of musical perception.

\section{Summary}

In summary, (see Supplemental Information C61) the musical group as a whole is dominated by two primary regions: frontal and temporal. The frontal cortex (132 cites, 39\%) is followed by the motor cortex, premotor, dorsal premotor, and Brocas Area. The temporal cortex ( 80 cites, $24 \%$ ) is followed by superior temporal gyrus, primary auditory cortex and Wernickes Area.

The Musical Cognition skill unit has three primary regions dominant: frontal, temporal and parietal. The frontal unit is followed by motor cortex, premotor and Broca's Area. The temporal region is followed by superior temporal cortex and gyrus, primary auditory cortex and Heschls Gyrus. The parietal region is followed by the anterior / superior parietal lobule and precuneus. The Musical Perception skill unit is also dominated by the frontal and temporal cortices. The frontal cortex includes motor and primary auditory cortices and dorsal premotor. The temporal cortex includes the superior and anterior temporal gyrus. The Musical Production skill unit is also dominated by the frontal and temporal cortices. The frontal cortex includes the motor, premotor, primary motor cortices and Brocas Area. The temporal cortex includes the superior temporal gyrus, primary auditory cortex and Wernickes Area. The Melody-Pitch-Rhythm skill unit is dominated by the temporal and parietal cortices. The temporal cortex includes superior temporal cortex and superior / inferior temporal gyrus. The parietal cortex includes the inferior parietal lobule, supramarginal gyrus and angular gyrus.

Overall, the highest primary regions for three of the four skill units include both frontal and temporal regions with variability among the primary regions with much lesser values. Melody-Pitch-Rhythm is unique for having parietal and temporal for its highest primary regions. Each skill unit has its own unique sub-region pattern while having four sub-regions in common. Musical Perception has three sub-regions unique to it while Musical Cognition has two unique regions. Melody and Production have single sub-regions that are unique and not shared with either of the other two skill units.

\section{Summary Discussion and Conclusions}

A viable scientific description of complex phenomena such as intelligence requires a level of detail that can be useful to scientists as well as practitioners. MI theory described in Frames of Mind (1983) has proven to be a good guide for educators but less useful or dismissed by neuroscientists. Cerebral structures cited by Gardner for each intelligence, based on the limited neuroscience evidence available at the time, have proven to be both robust and limited. Like the proverbial tip of an iceberg, they pointed the way towards a large and complex neural architecture that is gradually being revealed by advanced neuro-imaging techniques. Sophisticated research methods are also drawing closer connections between brain processes and educational practices.

Phase One of the ongoing, multi-phase investigation previously identified neural frameworks that are distinctive for each of the eight intelligences (Shearer \& Karanian, 2017). This high-level analysis confirms that the theoretical model proposed by Gardner has a coherent neural basis and suggests an integration of MI theory with general intelligence. But these findings are limited to the broad, general conception for each of the intelligences. It is important to keep in mind that individual intelligences are a composite of specific skills and cognitive performances. The present study reviewed the neuroscience evidence to test the hypothesis that these skill units form coherent sub-divisions matched with a designated intelligence. The data revealed that the units have both shared and unique neural activation patterns aligned with known cognitive correlates. These patterns are reviewed at the primary and sub-region levels below. 
Table 4. A Tally of Primary Regions Cited for Skill Units by Frequency of Position

Primary Regions Tally

\begin{tabular}{llllll}
\hline & Position & & & \\
\hline Primary Region & $\mathbf{1}^{\text {st }}$ & $\mathbf{2}^{\text {nd }}$ & $\mathbf{3}^{\text {rd }}$ & $\mathbf{4}^{\text {th }}$ & - \\
\hline Frontal & $\mathbf{1 3}$ & 7 & 1 & 2 & 2 \\
\hline Temporal & 6 & 7 & 4 & 4 & - \\
\hline Parietal & 4 & $\mathbf{9}$ & 6 & $\mathbf{7}$ & 1 \\
\hline Cingulate & - & 3 & 4 & $\mathbf{8}$ & 2 \\
\hline Occipital & - & 1 & 2 & 3 & $\mathbf{3}$ \\
\hline Subcortical & 1 & 3 & $\mathbf{8}$ & 4 & 2 \\
\hline Insular & - & - & 1 & 5 & 2
\end{tabular}

Note. Bold indicates most prominent number of citations for that region.

Primary Region Analysis

Supplemental Information C55 - C61 (comprised of tables for the seven intelligences) graphically displays the hierarchy of primary neural regions cited in the literature for each skill unit. Differences and similarities among skill units are evident. Table 24 (above) summarizes the frequency of these primary neural citations for each skill unit. What is striking about this table is the scatter among the primary regions and that five of the eight regions score quite highly on distinct levels. Frontal is highest for first place (13); parietal is the highest for second place (9) (followed closely by frontal (7) and temporal (7); subcortical is highest for third place; occipital (8) and cingulate (7) are highest for fourth place; and finally, again subcortical (3) is highest for fifth place among several regions with low level citations.

Frontal, temporal and parietal are noteworthy for two reasons. First, they are among the most frequently cited neural regions associated with general intelligence (Basten, Hilger \& Fiebach, 2015; Duncan, et al, 2000; Grabner, et al, 2006; Jung \& Haier, 2007) This suggests that each intelligence has its own complex reasoning and problem-solving dimensions similar to those employed by general intelligence. Second, these regions have been described as "neural hotspots of evolutionary expansion" (Hill, et al, 2010; Van Essen, et al, 2007). This is in line with one of the key pieces of evidence cited by Howard Gardner supporting his contention that these abilities qualify as forms of "intelligence" that have promoted the development of human civilization and are instrumental to meaning making.

Conversely, these data and previous investigations (Shearer \& Karanian, 2017; Shearer, 2017a) show that numerous neural regions beyond those associated with general intelligence are involved in the processing of the different intelligences. For example, subcortical and occipital regions score highly in the third and fourth positions, respectively. These values may be at lower levels but their importance to intelligences as diverse as logical-mathematical and musical is not insignificant.

Table 5. Sub-Regions Unique and Common Among Skill Units Per Intelligence

\begin{tabular}{llll} 
Summary & & & \\
\hline Intelligence & Unique & $\begin{array}{l}\text { Shared by } \\
2 \text { or } 3\end{array}$ & $\begin{array}{l}\text { Common } \\
\text { to All }\end{array}$ \\
\hline Interpersonal & 12 & 1 & 4 \\
\hline Intrapersonal & 12 & 3 & 3 \\
\hline Linguistic & 14 & 5 & 2 \\
\hline Logical-mathematical & 13 & 4 & 2 \\
\hline Visual-spatial & 10 & 9 & 2 \\
\hline Kinesthetic & 9 & 8 & 2 \\
\hline Musical & 7 & 10 & 4 \\
\hline Mean & $\mathbf{1 1}$ & $\mathbf{5 . 7}$ & $\mathbf{2 . 7}$
\end{tabular}




\section{Sub-Region Analysis}

It is important to carefully examine the activation patterns of sub-regions within a primary region because these smaller neural structures are often associated with more specific kinds of cognitive activity. The tally of sub-regions displayed in Table 5 that are common to all skill units (column four, within their designated intelligence) ranges from two to four $(m=2.7)$. The tally of sub-regions that are cited as unique to a designated skill unit ranges from seven to fourteen $(m=11)$. The average number of sub-regions that are shared by two or three skill units is 5.7, ranging from one to ten. These data indicate that the skill units within each intelligence have a common neural basis with additional neural structures to process their specific cognitive-behavioral aspects.

For example, the four shared neural sub-regions for musical intelligence (Fig. 7 and Supplemental B51) are the motor cortex, superior temporal gyrus, prefrontal gyrus, and inferior parietal lobule. Unique to the skill unit Musical Cognition are two regions: inferior temporal and middle frontal cortices. This combination is identified with several cognitive skills related to working memory, planning, executive functions and visual / object learning. There are many such rich and intriguing correlations between groups of neural regions and related cognitive performances worthy of further explication that is beyond the scope of this report.

\subsection{Conclusions}

The present investigation uncovered neural evidence indicating that within each intelligence are cognitive-skill units that have their own neural uniqueness and commonalities. These shared and unique neural activation patterns are evident in both large (primary) regions as well as smaller sub-regions.

The metaphor that applies to this analysis is that of a tree. The trunk represents the whole brain with branches for each intelligence. Second level branches represent skill units growing from each intelligence. Twigs and leaves represent particular activities associated with each skill unit. For example, letter-sound decoding is a twig-leaf for reading (a branch) that is supported by its main branch of linguistic intelligence that grows from the trunk. The trunk is comprised of multiple layers that sustain all the intelligences: logical reasoning, insight-intuition, aesthetic judgement, and creative cognition (Calvo-Merino. et al, 2007; Fink, 2007; Shearer, 2019). Highly skilled reading involves both specific skills associated with language processing but also this array of generic abilities.

\subsection{Implications}

There are three potential implications emanating from this investigation. First, the development of any new scientific theory rarely emerges fully realized in a single effort. Frames of Mind is a comprehensive description of MI theory with brief descriptions of several neural regions associated with each of the seven intelligences. Extensive accounts of many other kinds of data are provided in support of Gardner's contention that intelligence is best characterized as multiple rather than singular. The present analysis adds multiple layers of neural description to the frameworks underpinning each of the intelligences and their constituent skill units.

These descriptions provide a detailed neural architecture for what has previously had only a sketchy outline of key neural elements. Neuroscientists study specific behaviors and then extrapolate from the data to infer broader abstract abilities. The theory of multiple intelligences has been difficult to investigate directly due to the abstract nature of the designated intelligences as composites of skills and cognitive performances. The neural architecture presented here offers a detailed roadmap of specific behaviors amenable to experimental research not previously available.

Lastly, this work describes the neural features underlying specific cognitive behaviors that are the target of instruction in schools and classrooms, e.g., reading, mathematical reasoning, musical performance, and whole body movement, etc. MI theory has inspired many educators to alter instruction, curriculum, and school design without this knowledge, however, many of these efforts have been difficult to deploy widely. The emerging field of educational cognitive neuroscience strives to apply its findings from the lab to the classroom in a way that can be systematic and replicable without over-simplification (Goswami \& Szucs, 2011). This dichotomy between the science of brain research and the art of instruction has been described as a "bridge too far" by Bruer (1997). The detailed neural architecture described here represents a practical interface between instructional efforts and insights about how the brain operates (Immordino-Yang \& Gotlieb, 2016; Schwartz, 2015; Tokuhama-Espinosa, 2010). A goal of MI-inspired instruction is to use a student's strengths to create "personalized" curriculum that promotes the development of academic (IQ-based) skills (Chen, Krechevsky \& Viens, 1998; Hale, et al, 2016; Neubauer, et al, 2005). 


\subsection{Limitations and Future Directions}

The goal of this investigation is to examine the neural validity of skill units underlying seven intelligences as described by MI theory. The foundation of validity is the reliability of the data. First, to ensure validity, we selected well-designed, peer reviewed neuroscientific studies that examined neural activity carefully matched with the core cognitive / behavioral components comprising each of the intelligences. To enhance reliability, we included data from numerous experiments as a form of inter-rater reliability. The tables summarizing these statistics do not measure the strength of the activation patterns between MI theory and the brain, but rather reflect the confidence that we can have that the findings have been replicated by more than one observer or experiment. When multiple experiments agree that particular neural structures are associated with specific cognitive / behaviors, we can have confidence that such a relationship is robust and accurate.

There are a several limitations to this approach. First, even one well-designed experiment may produce valid results that have not yet been replicated by other researchers. Second, at any given point in time groups of neuroscientists may be focused on specific neural regions or cognitive-behaviors while other brain areas are neglected. Both possibilities mean that we need to view our findings here as a basic framework that needs to be elaborated and reorganized as the science progresses. Neural regions with just a few citations might be viewed as candidates for inclusion in the framework for that intelligence. Third, the dynamic interactions among the various neural structures detailed in this framework also require more study and description. Fourth, the relationship between the size of the neural structure and its impact on the cognitive / behavioral performance is uncertain and requires future clarification.

Previous reviews of the neuroscience literature concluded that the concept of general intelligence is included in the theory of multiple intelligences as a composite of the logical-mathematical and linguistic intelligences. This conclusion is supported by the present findings. To perceive IQ and MI as incompatible formulations is more of a cultural distinction as opposed to a conclusion based on the neural evidence. If educational institutions are to serve all students' development regardless of cultural background and neural configurations, we need to be cognizant of how our assumptions about intelligence impact instruction, curriculum, and school design. As our brain knowledge expands so too must our consideration of cognitive tools thought to be of value as instructional strategies.

Jung and Haier (2008) (quoted earlier) stated that “.... neuroscience approach that recognizes the importance of individual differences and the necessity to evaluate each student as an individual" is required to apply neuroscientific evidence to education. When our assumptions and assessments include the rich diversity of intellectual products embodied by the theory of multiple intelligences (Chen, Krechevsky \& Viens, 1998), we will have made significant progress toward the creation of a workable interface between neuroscience and the daily practice of teaching that unlocks human potential—one unique brain at a time.

\section{References}

Adolphs, R. (2009). The social brain: Neural basis of social knowledge. Annu Rev Psychol, 60, 693-716. https://doi.org/10.1146/annurev.psych.60.110707.163514

Aziz-Zadeh, L., Liew, S. \& Dandekar, F. (2013). Exploring the neural correlates of visual creativity. SCAN 8, 475 - 480. https://doi.org/10.1093/scan/nss021

Barbey, A.K. \& Barsalou, L.W. (2009). Reasoning and problem solving: Models. Encyclopedia of Neuroscience, 8, pp. 35-43. https://doi.org/10.1016/B978-008045046-9.00435-6

Barbey, A.K., Colom, R., Solomon, J., Krueger, F., Forbes \& C. Grafman, J. (2012). An integrative architecture for general intelligence and executive function revealed by lesion mapping. Brain. https://doi.org/10.1093/brain/aws021

Basten, U., Hilger, K. \& Fiebach, C. J. (2015). Where smart brains are different: A quantitative meta-analysis of functional and structural brain imaging studies on intelligence. Intelligence, 51, 10-27. http://dx.doi.org/10.1016/j.intell.2015.04.009

Blair, C. (2006). How similar are fluid cognition and general intelligence? A developmental neuroscience perspective on fluid cognition as an aspect of human cognitive ability. Behavioral and Brain Sciences, 29, 109 - 160. https://doi.org/10.1017/S0140525X06009034

Brody, N. (1992). Intelligence. New York: Academic Press.

Brown S, Martinez MJ \& Parsons L.M. (2006). The neural basis of human dance. Cereb Cortex, 16, 1157-1167. https://doi.org/10.1093/cercor/bhj057 
Bruer, J. T. (1997). Education and the brain: A bridge too far. Educational Researcher, 26, 4-16. https://doi.org/10.3102/0013189X026008004

Calvo-Merino, B. et al. (2007). Towards a sensorimotor aesthetics of performing art. Consciousness and Cognition, 17, 911- 922. https://doi.org/10.1016/j.concog.2007.11.003

Chen, J., Krechevsky, M. \& Viens, J. (1998). Building on children's strengths: The experience of project spectrum. New York: Teachers College Press.

Chen, J., Moran, S. \& Gardner, H. (Ed.) (2009). Multiple intelligences around the world. San Francisco, CA: Jossey-Bass.

Chomsky, N. (2009). A conversation about multiple intelligences / an interview with Noam Chomsky. in MI at 25: Assessing the impact and future of multiple intelligences for teaching and learning. New York: Teachers College Press.

Cui, X. (2007). Vividness of mental imagery: Individual variability can be measured objectively. Vision Research, 47, 474-478. https://doi.org/10.1016/j.visres.2006.11.013

Damasio, A. (2003). Mental self: The person within. Nature, 423 (6937), 227. https://doi.org/10.1038/423227a

Decety, J, Skelly, L. \& Kiehl, K.A. (2013). Brain response to empathy-eliciting scenarios involving pain in incarcerated individuals with psychopathy. JAMA Psychiatry, 70(6), 638-645. https://doi.org/10.1001/jamapsychiatry.2013.27

Dehaene, S., Molko, M., Cohen, L. \& Wilson, A. (2004). Arithmetic and the brain. Current Opinion in Neurobiology, 14, 218-224. https://doi.org/10.1016/j.conb.2004.03.008

Duncan, J. (2013). The structure of cognition: Attentional episodes in mind and brain. Neuron, 80, 35 - 50. https://doi.org/10.1016/j.neuron.2013.09.015

Duncan, J. et al. (2000). A neural basis for general intelligence. Science, 289, 457. https://doi.org/10.1126/science.289.5478.457

Fink, A. et al. (2007). Creativity meets neuroscience: Experimental tasks for the neuroscientific study of creative thinking. ScienceDirect, 42, 68 - 76. https://doi.org/10.1016/j.ymeth.2006.12.001

Gardner, H. (1983). Frames of mind: The theory of multiple intelligences. New York: Basic Books.

Gardner, H. (1999). Intelligence reframed: Multiple intelligences for the $21^{\text {st }}$ century. New York: Basic Books.

Gaser, C. \& Schlaug, G. (2003). Brain structures differ between musicians and non-musicians. J. Neurosci, 23, 9240-9245. https://doi.org/10.1523/JNEUROSCI.23-27-09240.2003

Gerin, B. \& Fien, H. (2016). Translating the neuroscience of physical activity to education. Trends in Neuroscience and Education, 5, 12-19. https://doi.org/10.1016/j.tine.2016.02.001

Goleman, D. (1995). Emotional intelligence. New York: Bantam.

Goswami, U., \& Szucs, D. (2011). Educational neuroscience: Developmental mechanisms: Towards a conceptual framework. NeuroImage, 57, 651-658. https://doi.org/10.1016/j.neuroimage.2010.08.072

Gottfredson, L. (Summer, 2004). Schools and the g factor. Wilson Quarterly. Washington, DC. The Woodrow Wilson International Center for Scholars.

Grabner, R. et al, (2006). Superior performance and neural efficiency: The impact of intelligence and expertise. Brain Research Bulletin, 69, 422-439. https://doi.org/10.1016/j.brainresbull.2006.02.009

Guilford, J. L. (1954). The nature of human intelligence. New York: McGraw-Hill.

Haier, R. \& Jung, R. (2008). Brain imaging studies of intelligence and creativity: What is the picture for education? Roeper Review, 30(3), 171-180. https://doi.org/10.1080/02783190802199347

Hale, J.B., et al. (2016). Reconciling individual differences with collective needs: The juxtaposition of social political and neuroscience perspectives on remediation and compensation of student skill deficits. Trends in Neuroscience and Education, 5, 41-51. https://doi.org/10.1016/j.tine.2016.04.001

Hampshire, A., et al. (2012). Fractionating human intelligence. Neuron, 76, 1225 - 1237. https://doi.org/10.1016/j.neuron.2012.06.022

Herrnstein, R., \& Murray, C. (1994). The bell curve. New York: Free Press. 
Hill, J. et al. (2010) Similar patterns of cortical expansion during human development and evolution. PNAS, 107(29), 13135-13140. https://doi.org/10.1073/pnas.1001229107

Immordino-Yang, M.H. \& Gotlieb, R. (2016). Embodied brains, social minds, cultural meaning: Integrating neuroscientific and educational research on social-affective development (Manuscript accepted). American Educational Research Journal: Centennial Issue. https://doi.org/10.3102/0002831216669780

Jantzen, K., Steinberg, F. \& Kelso, J. (2008). Coordination dynamics of large-scale neural circuitry underlying rhythmic sensorimotor behavior. Journal of Cognitive Neuroscience, 21(12), 2420-2433. https://doi.org/10.1162/jocn.2008.21182

Jensen, A. (1999). The g factor: the science of mental ability. Psycoloquy. American Psychological Assn. http://psychprints.ecs.soton.ac.uk/archive/00000658/

Jung, R. E., \& Haier, R. J. (2007). The Parieto-Frontal Integration Theory (P-FIT) of intelligence: Converging neuroimaging evidence. Behavioral and Brain Sciences, 30, 135-187. https://doi.org/10.1017/S0140525X07001185

Kolb, A. Y., \& Kolb, D. A. (2005). The Kolb learning style inventory - version 3.1: 2005 technical specifications. Boston: Hay Transforming Learning. www.haygroup.com/tl.

McCandliss, B. \& Noble, K. (2003). The development of reading impairment: A cognitive neuroscience model. Mental Retardation And Developmental Disabilities. Research Reviews, 9, 196-205. https://doi.org/10.1002/mrdd.10080

Neubauer, A. et al. (2005). Intelligence and neural efficiency: Further evidence of the influence of task content and sex on the brain-IQ relationship. Cognitive Brain Research, 25, 217-225. https://doi.org/10.1016/j.cogbrainres.2005.05.011

Northoff, G., Heinzel, A., de Greck, M., Bermpohl, F., Dobrowolny, H. \& Panksepp, J. (2006), Self-referential processing in our brain-A meta-analysis of imaging studies on the self. NeuroImage, 31(1), 440-457. 18p. https://doi.org/10.1016/j.neuroimage.2005.12.002

Posner, M. (2013). The expert brain. In Expertise and Skill Acquisition: The Impact of William G. Chase. NY: Psychology Press.

Posner, M., Rothbart, M., Sheese, B. \& Kieras, J. (March, 2008). Arts and cognition monograph: How arts training influences cognition, Dana Foundation, downloaded 2014. http://dana.org/Publications/ReportDetails.aspx?id=44253

Price, C. (2012). A review and synthesis of the first 20 years of PET and fMRI studies of heard speech, spoken language and reading. NeuroImage 62. 816-847. https://doi.org/10.1016/j.neuroimage.2012.04.062

Qiu, J. et al. (2008) The neural basis of insight problem solving: An event-related potential study. Brain and Cognition, 68, (100-106). https://doi.org/10.1016/j.bandc.2008.03.004

Sadaghiani, S. et al. (2010). The relation of ongoing brain activity, evoked neural responses, and cognition. Front. Syst Neuroscience, 4, 20. https://doi.org/10.3389/fnsys.2010.00020

Salovey, P., \& Mayer, J. D. (1990). Emotional intelligence. Imagination, Cognition, and Personality, 9, 185-211. https://doi.org/10.2190/DUGG-P24E-52WK-6CDG

Schwartz, M. (June, 2015). Mind, brain and education: A decade of evolution. Mind, Brain and Education, 9, 2. https://doi.org/10.1111/mbe.12074

Shearer, C. B. \& Karanian, J.M. (2017). The neuroscience of intelligence: Empirical support for the theory of multiple intelligences? Trends in Neuroscience and Education, 6, 211-223. https://doi.org/10.1016/j.tine.2017.02.002

Shearer, C. B. (2019). Cognitive neuroscience of the multiple intelligences: describing the neurocognitive differences among ability groups. Manuscript submitted for publication in Trends in Neuroscience and Education for a special issue entitled, Neuroscience of Human Intelligence.

Shearer, C. B. (March, 2017b). Creative Cognition, Insight / Intuition and Aesthetic Judgment: Investigating NeuroCognitive Qualities Integral to the Multiple Intelligences. Poster at Neuroscience of Creativity Annual Meeting, San Francisco, CA.

Shearer, C. B., (2017a). A Resting State Functional Connectivity Analysis of the Multiple Intelligences. Poster presented at Cognitive Neuroscience Society Annual Meeting, San Francisco. 
Sternberg, R. J. (1996). Successful intelligence. New York: Simon \& Schuster.

Sternberg, R.J. (1988). The triarchic mind. New York: Viking Press.

Thurstone, L.L. (1938). Primary mental abilities. Chicago: University of Chicago Press.

Tokuhama-Espinosa, T. (2010). Mind, Brain, and Education Science: A Comprehensive Guide to the New Brain-Based Teaching. New York: WW Norton.

Traub, J. \& Gardner, H. (1999). A debate on multiple intelligences. The Dana Foundation, downloaded 4-20-16 http://www.dana.org/Cerebrum/Default.aspx?id=39332

Van Essen, David C. et al. (2007). Surface-Based and Probabilistic Atlases of Primate Cerebral Cortex. Neuron, 56(2), 209 - 225. https://doi.org/10.1016/j.neuron.2007.10.015

Visser, B., Ashton, M. \& Vernon, P. (2006). Beyond g: Putting multiple intelligences theory to the test. Intelligence, 34, 487-502. https://doi.org/10.1016/j.intell.2006.02.004

Waterhouse, L. (2006a). Multiple intelligences, the Mozart effect, and emotional intelligence: A critical review. Educational Psychologist, 41, 207-225. https://doi.org/10.1207/s15326985ep4104_1

Waterhouse, L. (2006b). Inadequate evidence for multiple intelligences, Mozart effect, and emotional intelligence theories. Educational Psychologist, 41, 247-255. https://doi.org/10.1207/s15326985ep4104_5

White, J. (1988). Do Howard Gardner's multiple intelligences add up? London: Institute Of Education, University of London.

Willingham, D.T. (2004). Reframing the mind. Retrieved 10-1-04 from http://educationnext.org/20043/18.html

Zatorre, R., \& Salimpoor, V. (2013). From perception to pleasure: Music and its neural substrates. PNAS, 110, suppl. https://doi.org/10.1073/pnas.1301228110 


\section{Notes:}

*To qualify as an intelligence, each set of abilities has to fair reasonably well in meeting eight criteria as specified in Frames of Mind, 1983, p. 62 - 67:

1- identifiable cerebral systems

2- evolutionary history and plausibility

3- core set of operations

4- meaning encoded in a symbol system

5- a distinct developmental history \& mastery

6- savants, prodigies and exceptional people

7- evidence from experimental psychology

8- psychometric findings

Definition: Intelligence is a biopsychological potential to process information that can be activated in a cultural setting to solve problems or create products that are of value in a culture. Intelligence Reframed (1999).

** Haier and Jung (2008, p. 173) describe a widely distributed neural network model that underpins intelligence called the Parieto-Frontal Integration Theory (P-FIT) involving the frontal lobes, parietal, temporal and occipital cortices.

"The P-FIT recognizes that our species gathers and processes information predominantly through auditory and/or visual means, usually in combination; thus, particular brain regions within the temporal and occipital lobes are critical to early processing of sensory information: the extrastriate cortex (BAs 18, 19) and fusiform gyrus (BA 37), involving recognition and subsequent imagery and/or elaboration of visual input, and Wernicke's area (BA 22), involving analysis and/or elaboration of syntax of auditory information. This basic sensory processing is then fed forward to the parietal cortex, predominantly the supramarginal (BA 40), inferior parietal (BA 7), and angular (BA 39) gyri, wherein structural symbolism and/or abstraction of the current set to alternative cognitive sets are generated and elaborated. The parietal cortex interacts with frontal regions (i.e., BAs 6, 9, 10,45-47), which serve to hypothesis test various solutions to a given problem. Once the best solution emerges, the anterior cingulate (BA 32) is engaged to constrain response selection as well as inhibition of other competing responses. This process is critically dependent upon the fidelity of underlying white matter needed to facilitate rapid and error free transmission of data from posterior to frontal brain regions.

No conflicts of interest are noted.

This research did not receive funding from any sources.

Supplemental Information cited in the text are available from the author- sbranton@kent.edu.

\section{Copyrights}

Copyright for this article is retained by the author(s), with first publication rights granted to the journal.

This is an open-access article distributed under the terms and conditions of the Creative Commons Attribution license (http://creativecommons.org/licenses/by/4.0/). 